\title{
LA INCONSTITUCIONALIDAD DE LA LEY INTERNA POR VULNERACIÓN DEL DERECHO DE LA UNIÓN EUROPEA
}

\author{
GUSTAVO MANUEL DÍAZ GONZÁLEZ' \\ Universidad de Constanza \\ gustavo-manuel.diaz-gonzalez@uni-konstanz.de
}

Cómo citar/Citation

Díaz González, G. M. (2017).

La inconstitucionalidad de la ley interna por vulneración del derecho de la Unión Europea. Revista de Administración Pública, 202, 91 -130. doi: https://doi.org/10.18042/cepc/rap.202.03

\section{Resumen}

El Tribunal Constitucional español ha rechazado tradicionalmente declarar su competencia para enjuiciar la validez de ley nacional desde la perspectiva de su conformidad con el derecho de la Unión Europea, al amparo de una interpretación restrictiva de la doctrina Simmenthal del Tribunal de Justicia. Las jurisdicciones constitucionales de otros Estados miembros, sin embargo, han optado por atribuir a las disposiciones de aquel sistema el carácter de parámetro de constitucionalidad de la ley nacional con pleno respeto del papel del juez ordinario como garante inmediato del derecho de la Unión. En este trabajo se aborda el estudio de las referidas construcciones y se formula una propuesta conclusiva sobre la apertura de nuestra jurisprudencia constitucional en la línea apuntada.

Investigador postdoctoral. Cátedra de Derecho Constitucional, Administrativo, Europeo y Comparado, dirigida por el profesor Dr. D. Hans C. Röhl. Es asimismo miembro del grupo de investigación Derecho Administrativo de la Universidad de Oviedo, dirigido por Alejandro Muergo Lora. 


\section{Palabras clave}

Primacía del derecho de la Unión Europea; doctrina Simmenthal; control de constitucionalidad.

\section{Abstract}

The Spanish Constitutional Court has traditionally excluded its own competence to declare the invalidity of an internal Act because of its incompatibility with European Union Law, based on a restrictive understanding of the Simmenthal case law of the Court of Justice of the European Union. Constitutional Courts in other Member States have nevertheless recognized the character of European Union Law as parameter of validity of national Acts with full respect to the role of ordinary courts as main guardians of that legal system. This paper aims to critically comment those foreign rulings and proposes the revision of our constitutional jurisprudence with the referred approach.

\section{Keywords}

Primacy of European Union Law; Simmenthal case law; constitutional review. 


\section{SUMARIO}

I. INTRODUCCIÓN. II. LA AMPLIACIÓN DEL PARÁMETRO DE CONSTITUCIONALIDAD DE LA LEY INTERNA EN EL ORDENAMIENTO FRANCÉS: LA OBLIGACIÓN DE TRANSPOSICIÓN DE LAS DIRECTIVAS EUROPEAS COMO EXIGENCIA CONSTITUCIONAL: 1. La fiscalización de la Ley de transposición de una Directiva a través del recurso previo de constitucionalidad. 2. La cuestión prioritaria de constitucionalidad como cauce procesal para la verificación de la adecuación de la ley a la directiva. III. EL PROBLEMA EN EL SISTEMA ITALIANO: ¿̇LA DISPOSICIÓN EUROPEA COMO CANON DE VALIDEZ DE LA LEY NACIONAL?: 1. Introducción. El complejo "camino comunitario" de la Corte costituzionale hasta la asimilación de la doctrina Simmenthal. 2. Ulteriores desarrollos de la jurisprudencia de la Corte costituzionale: la exploración de los intersticios de la doctrina Granital. 3. La reforma del artículo $117.1 \mathrm{Cl}$ y la definitiva consagración del artículo $11 \mathrm{Cl}$ como fundamento de la competencia de la Corte. 4. La reciente Sentencia 133/2016, de 19 de abril: żun paso atrás? IV. CONCLUSIONES. BREVE EXCURSO SOBRE LA PERTINENCIA DE LA APERTURA DEL CONTROL DE CONSTITUCIONALIDAD DE LA LEY NACIONAL EN CLAVE EUROPEA.

\section{INTRODUCCIÓN}

La lectura del principio de primacía del derecho de la Unión Europea con respecto a los ordenamientos nacionales en clave exclusivamente aplicativa es una constante en la jurisprudencia constitucional de la práctica totalidad de Estados miembros. La idea de que la inobservancia de los vínculos de derecho europeo por parte del legislador nacional se traduce en un conflicto tan solo resoluble a través de la inaplicación, por parte del juez ordinario, de la disposición de derecho interno, que continúa en vigor en tanto el órgano competente no proceda a su derogación o modificación, ha alcanzado el estatus de dogma, por su condición de tal inalterable, pese a incardinarse en un ámbito como el del sistema de relaciones interordinamentales, objeto de permanente revisión. En esta línea, y pese a los tan destacados desarrollos que 
la cuestión europea ha conocido en la última década en la jurisprudencia del Tribunal Constitucional español ${ }^{2}$, resiste inconmovible la negación de toda relevancia, aun desde la perspectiva del artículo $93 \mathrm{CE}$, a la conculcación del derecho de la Unión en el juicio de constitucionalidad de la ley³. Nuestro Tribunal Constitucional, con el apoyo (cuando menos implícito) en este punto de la mejor doctrina ${ }^{4}$, se adhiere, así, a la consolidada construcción alemana,

2 Desarrollos que, en todo caso, han quedado circunscritos al ámbito del recurso de amparo: como es bien sabido, a partir de la STC 58/2004, de 19 de abril, el Tribunal Constitucional ha reconocido la lesión del derecho fundamental a la tutela judicial efectiva en los supuestos de falta de planteamiento de la cuestión prejudicial ante el Tribunal de Justicia por el juez ordinario, en el caso de ser la misma preceptiva (doctrina ratificada, si bien con vaivenes, en las SSTC 194/2006, de 19 de junio, 78/2010, de 20 de octubre, 27/2013, de 11 de febrero, y 212/2014, de 18 de diciembre); idéntico ha sido el pronunciamiento del Tribunal Constitucional en los casos en los que el órgano de la jurisdicción ordinaria ha resuelto en contra de la interpretación de la norma europea aplicable al caso previamente fijada por el Tribunal de Justicia (SSTC 145/2012, de 2 de julio, 232/2015, de 5 de noviembre, y 148/2016, de 19 de septiembre); el propio Tribunal Constitucional, en fin, ha dirigido una consulta en vía prejudicial al Tribunal de Justicia, rectificando posteriormente su propia jurisprudencia sobre la condena penal en rebeldía, en el conocido asunto Melloni (ATC 86/2011, de 9 de junio, y STC 26/2014, de 13 de febrero). Muy recientemente ha querido verse en esta europeización del recurso de amparo una anticipación de la extensión del fenómeno al parámetro de constitucionalidad de la ley interna; véase, en este sentido, L. Martín Rebollo (2016), «Sobre el papel del juez nacional en la aplicación del Derecho europeo y su control», Revista de Administración Pública, 200, págs. 173-192 (pág. 182).

3 Cfr., entre los últimos pronunciamientos que recogen esta doctrina, la ya citada STC 232/2015, de 5 de noviembre (FJ $4^{\circ}$ ).

4 En este sentido, con matices, E. García de Enterría y T.-R. Fernández (2015), Curso de Derecho Administrativo, I, Cizur Menor: Civitas, $17^{\text {a }}$ edición, pág. 181; A. Mangas Martín y D. Liñán Nogueras (2015), Instituciones y Derecho de la Unión Europea, Madrid: Tecnos, 8a edición, pág. 488 (sobre la postura de estos autores, precisada más adelante por medio de la diferenciación de las posibilidades de fiscalización del Tribunal Constitucional en función del tipo de procedimiento en el que se ponga de manifiesto la antinomia entre la ley nacional y la disposición europea, habrá de volverse en el apartado conclusivo de este trabajo); P. Cruz Villalón y J. L. Requejo Pagés (2015), «La relación entre la cuestión prejudicial y la cuestión de inconstitucionalidad», Revista de Derecho Comunitario Europeo, 50, págs. 173-194 (pág. 179); J. A. Santamaría Pastor (2016), Principios de Derecho Administrativo General, I, Madrid: Iustel, 4a edición, pág. 200 (el autor menciona el pasaje de la Sentencia Simmenthal sobre el efecto bloqueo del derecho de la Unión Europea con respecto a la norma estatal posterior, pero no profundiza en la posibilidad de utilización, sobre esa base, 
que, en la exposición de las implicaciones del principio de primacía, rechaza que el mismo despliegue efectos sobre la validez de la norma interna contraria al derecho europeo, afectando, por el contrario, tan solo a su aplicabilidad5:

de una técnica de control jurisdiccional diferente de la inaplicación de la disposición interna en caso de conflicto); y D. Sarmiento (2016), El Derecho de la Unión Europea, Madrid: Marcial Pons, pág. 314. En contra, destacan las reflexiones de R. Alonso García (2014), Sistema jurídico de la Unión Europea, Cizur Menor: Aranzadi, 4a edición, págs. 329-331, que, apoyándose en la no exclusión por la jurisdicción europea del recurso a procedimientos complementarios con respecto a la inaplicación de la norma nacional contraria al ordenamiento europeo orientados a la declaración de la nulidad de la misma, siempre que «resulten apropiados para salvaguardar los derechos individuales» reconocidos por este sistema (Sentencia del Tribunal de Justicia de 22 de octubre de 1998, asuntos acumulados C-10/97 a C-22/97, IN.CO.GE., ap. 21), y con mención de la postura favorable del Consejo de Estado (Informe de 14 de febrero de 2008, sobre la inserción del derecho europeo en el ordenamiento espańol), defiende incluso que los principios de seguridad jurídica y equivalencia podrían servir de base a una extensión de la competencia de la jurisdicción constitucional nacional en materia de control de la adecuación de la ley nacional al derecho de la Unión. Igualmente sólida es, en este sentido, la exposición de S. Muñoz Machado (2015), Tratado de Derecho Administrativo y Derecho Público General, IV: El ordenamiento jurídico, Boletín Oficial del Estado, 4a edición, págs. 234-235 y 238-239, que critica desde la perspectiva de la racionalidad del sistema jurídico la admisión de la existencia de normas simultáneamente vigentes e inaplicables y considera que, no obstante la comprensible inhibición de la jurisprudencia europea, que tan solo exige, en los supuestos de conflicto, la inaplicación de la disposición nacional, nuestro derecho constitucional impone con evidencia la aplicación de la sanción de nulidad.

5 La doctrina alemana distingue, así, entre primacía aplicativa (Anwendungsvorrang) y primacía de validez (Geltungsvorrang), rechazando esta última interpretación del principio en el ámbito de las relaciones entre los ordenamientos jurídicos europeo y nacional: vid., en este sentido, entre otros muchos, H. P. Ipsen (1972), Europäisches Gemeinschaftsrecht, Tübingen: Mohr Siebeck, págs. 287-288; K. Stern (1984), Das Staatsrecht der Bundesrepublik Deutschland, I: Grundbegriffe und Grundfragen des Staatsrechts. Strukturprinzipien der Verfassung, München: Beck, 2a edición, pág. 544; U. Di Fabio (1990), «Richtlinienkonformität als ranghöchstes Normauslegungsprinzip? Überlegungen zum Einfluss des indirekten Gemeinschaftsrechts auf die nationale Rechtsordnung», Neue Juristische Wochenschrift, págs. 947-954 (págs. 950-951); N. Lorenz (1990), Die Übertragung von Hoheitsrechten auf die Europäischen Gemeinschaften, Frankfurt: Peter Lang, pág. 93; H. D. Jarass (1994), Grundfragen der innerstaatlichen Bedeutung des EG-Rechts, Köln/Berlin/Bonn/München: Carl Heymanns Verlag, pág. 3; J. Isensee (1997), "Vorrang des Europarechts und deutsche Verfassungsvorbehalte - offener Dissens», en J. Burmeister (ed.), Verfassungsstaatlichkeit. Festschrift für 
la repercusión estrictamente constitucional del principio de primacía en aquel sistema se limita, de esta forma, a la adición de una interpretación de signo europeísta del inciso del artículo 20 III GG en el que se proclama la sujeción del juez a la ley y al derecho ${ }^{6}$.

Frente a esta visión del problema, las jurisdicciones constitucionales de algunos Estados miembros han afirmado su propia competencia para declarar

Klaus Stern zum 65. Geburtstag, München: Beck, págs. 1239-1268 (págs. 1242-1243); A. Funke (2007), «Der Anwendungsvorrang des Gemeinschaftsrechts - Einige Problemfälle und ein Präzisierungsvorschlag», Die Öffentliche Verwaltung, págs. 733-740 (pág. 736); H. Maurer (2012), «Der Anwendungsvorrang im Normensystem», en M. Sachs y H. Siekmann (eds.), Der grundrechtsgeprägte Verfassungsstaat. Festschrift für Klaus Stern zum 80. Geburtstag, Berlin: Duncker \& Humblot, págs. 101-115 (págs. 102-103); C. Vedder (2012), «Artikel 288 [ex-Artikel 249 EGV] (Die Rechtsakte der Union)», en C. Vedder y W. Heintschel von Heinegg (eds.), Europäisches Unionsrecht. EUVIAEUVIGrundrechte-Charta. Handkommentar, Baden-Baden: Nomos, págs. 942-967 (pág. 962); W. Schroeder (2013), Grundkurs Europarecht, München: Beck, $3^{a}$ edición, pág. 81, $\$$ 5.24; C. Calliess (2014), Staatsrecht III. Bezüge zum Völkerund Europarecht, München: Beck, págs. 297-298, parte 3 D, par. 14; M. Nettesheim (2014), «Art. 288 [Rechtsakte; Katalog]», en E. Grabitz, M. Hilf y M. Nettesheim (eds.), Das Recht der Europäischen Union, III: EUVIAEUV, München: Beck, págs. 1-71 (pág. 19); A. Haratsch, C. Koenig y M. Pechstein (2014), Europarecht, Mohr Siebeck, Tübingen, 9a edición, pág. 86, par. 179; K. F. Gärditz (2014), «\$ 35 Verhältnis des Unionsrechts zum Recht der Mitgliedstaaten", en H.-W. Rengeling, A. Middeke y M. Gellermann (eds.), Handbuch des Rechtsschutzes in der Europäischen Union, München: Beck, 3a edición, págs. 633-676 (pág. 637), par. 7; A. Berger (2015), Anwendungsvorrang und nationale Verfassungsgerichte, Tübingen: Mohr Siebeck, pág. 17; y D. Ehlers (2015), "Verhältnis des Unionsrechts zu dem Recht der Mitgliedstaaten», en R. Schulze, M. Zuleeg y S. Kadelbach (eds.), Europarecht. Handbuch für die deutsche Rechtspraxis, Baden-Baden: Nomos, 3a edición, págs. $491-522$ (págs. 514-515). Una postura peculiar al respecto en la doctrina alemana puede encontrarse en K. F. Röhl y H. C. Röhl (2008), Allgemeine Rechtslehre, Köln/München: Carl Heymanns Verlag, $3^{a}$ edición, págs. 594-595: la exposición de los autores parte de que la diferenciación entre Geltungs- y Anwendungsvorrang es, en lo que al sistema de relaciones entre derecho europeo y derecho nacional respecta, tan solo teórica, toda vez que la comprensión no aplicativa del principio de primacía (Geltungsvorrang) comporta una reducción del ámbito de validez de la norma nacional contraria al ordenamiento de la Unión, que es lo que de hecho ocurre de acuerdo con la construcción comúnmente aceptada, de forma que la no declaración de nulidad de la disposición estatal que colisiona con el derecho europeo es, en realidad, un aspecto secundario.

6 Cfr. T. Kruis (2013), Der Anwendungsvorrang des EU-Rechts in Theorie und Praxis, Tübingen: Mohr Siebeck, pág. 147. 
la inconstitucionalidad de la ley interna contraria al derecho europeo. En este sentido, revisten especial interés las doctrinas aplicadas por el Conseil constitutionnel francés y, sobre todo, por la Corte costituzionale italiana, que, si bien no siempre con plena sujeción a lo afirmado en la sentencia Simmenthal del Tribunal de Justicia (asunto 106/77), han abierto la posibilidad de expulsar del ordenamiento nacional, con eficacia erga omnes, las disposiciones de rango legal que vulneran lo dispuesto en una norma del derecho de la Unión. Sobre estas líneas jurisprudenciales y su posible aplicación en nuestro país nos proponemos reflexionar en el presente trabajo.

Más allá de su interés intrínseco, la cuestión ha adquirido, tras la reforma constitucional de 27 de septiembre de 2011, por la que se dio una nueva redacción al artículo $135 \mathrm{CE}$, una renovada significación: a través de la específica mención de la sujeción de los poderes públicos nacionales a la normativa europea en materia de estabilidad presupuestaria se ha producido, en opinión de la doctrina mayoritaria, un refuerzo de dicha vinculación no en el plano europeo, sino en el interno, debiendo ańadirse ahora a la intervención fiscalizadora del juez ordinario y de la jurisdicción europea (a través del recurso por incumplimiento, con eventual imposición de una sanción económica) la de nuestro Tribunal Constitucional, obligado, así, a revisar su propia doctrina y a proceder a la apertura de una vía de verificación del respeto de aquellos vínculos ${ }^{7}$. No obstante nuestro sustancial acuerdo con esta afirmación, por cuanto una interpretación contraria comportaría una significativa minimización del alcance de la reforma constitucional, manifestamos ya en este momento, sin perjuicio de un ulterior desarrollo argumental en las conclusiones de este trabajo, que tal parcialidad de la reorientación de la jurisprudencia constitucional en la materia conduciría a un tratamiento asimétrico del derecho europeo desde la perspectiva interna, lo cual resulta incongruente con las reglas que disciplinan el sistema de relaciones entre ordenamientos. El replanteamiento de la cuestión habrá de ser, pues, en línea de principio, global,

En este sentido, véanse E. Alberti Rovira (2011), en AA VV, «La reforma del artículo 135 CE», Revista Española de Derecho Constitucional, 93, págs. 159-210 (pág. 166); E. Álvarez Conde (2012), «Presentación. La reforma (preventiva) constitucional de 2011», en E. Álvarez Conde y C. Souto Galván (dirs.), La constitucionalización de la estabilidad presupuestaria, Madrid: Instituto de Derecho Público/Universidad Rey Juan Carlos, págs. 17-43 (págs. 35 y ss.); A. Embid Irujo (2012), La constitucionalización de la crisis económica, Madrid: Iustel, esp. págs. 82-83; J. García-Andrade Gómez (2012), «La reforma del artículo 135 de la Constitución española», Revista de Administración Pública, 187, págs. 31-66 (págs. 41 y 59 y ss.); y V. Ruiz Almendral (2012), «Estabilidad presupuestaria y reforma constitucional», Revista Española de Derecho Europeo, 41, págs. 33-110 (págs. 84 y 95-96). 
y solo habrán de tomarse en consideración como criterios de reflexión y, en su caso, de limitación de las posibilidades que deja abiertas este nuevo enfoque sobre el parámetro de validez jurídico-constitucional de la ley, factores de alcance más amplio o transversal, tales como la (eventual) eficacia directa de las normas de derecho europeo que sirvan de canon de enjuiciamiento, el tipo de procedimiento de que se trate (recurso o cuestión de inconstitucionalidad) o, desde una perspectiva menos técnica, pero igualmente relevante, el papel de la jurisdicción constitucional como garante de las reglas y principios de la Norma Fundamental (singularmente, de los derechos fundamentales) y el peligro que para su satisfactorio desarrollo podría traer consigo una ampliación excesiva de su principal herramienta de trabajo, es decir, de las disposiciones a las que se encuentra vinculada en su función de fiscalización normativa. Sobre todos estos aspectos, la mirada al derecho comparado ofrece aportaciones jurisprudenciales y doctrinales de notable interés, a cuyo análisis dedicamos las siguientes páginas.

\section{LA AMPLIACIÓN DEL PARÁMETRO DE CONSTITUCIONALIDAD DE LA LEY INTERNA EN EL ORDENAMIENTO FRANCÉS: LA OBLIGACIÓN DE TRANSPOSICIÓN DE LAS DIRECTIVAS EUROPEAS COMO EXIGENCIA CONSTITUCIONAL}

\section{LA FISCALIZACIÓN DE LA LEY DE TRANSPOSICIÓN DE UNA DIRECTIVA A TRAVÉS DEL RECURSO PREVIO DE CONSTITUCIONALIDAD}

Son varios los factores que han contribuido a que la cuestión sea objeto, en el derecho francés, de un tratamiento cuando menos singular. Por un lado, el conjunto de disposiciones constitucionales de relevancia en este ámbito dibujan un marco normativo un tanto confuso: así, de una parte, el tenor literal del artículo 55 de la Constitución Francesa (en adelante, CFr), que consagra el principio de la subordinación de la ley al tratado internacional, no aclara en qué consiste (rectius: qué consecuencias presenta desde el punto de vista de su fiscalización jurisdiccional) dicho criterio de ordenación jerárquica de las normas ${ }^{8}$, lo cual favorece, a priori, la defensa de las más variopintas

8 Dispone el artículo 55 CFr que «los tratados o acuerdos válidamente ratificados o aprobados gozan, a partir del momento de su publicación, de una autoridad superior a la de las leyes, condicionada, para cada tratado o acuerdo, a su aplicación por las demás partes». En relación con la problemática de la interpretación de este precepto 
interpretaciones del citado precepto; de otra, el artículo $61 \mathrm{CFr}$, al regular las líneas maestras del control de constitucionalidad de la ley nacional por medio del recurso directo, de naturaleza exclusivamente preventiva, menciona tan solo a la propia Constitución como parámetro; por último, el título XV, introducido por la reforma constitucional de 1992, prevé la participación de la República francesa en el proceso de integración europea (artículo 88-1 CFr) y dispone la sujeción de los poderes públicos nacionales a concretos ámbitos de las políticas de la arquitectura institucional del derecho originario? ${ }^{9}$ Por otro lado, las jurisdicciones constitucional y contenciosa de aquel país no han ocultado, tradicionalmente, sus reservas frente al principio de primacía del ordenamiento europeo, procediendo con sumo retraso a su recepción, lo cual ha contribuido, como se tendrá ocasión de comprobar, a la elaboración de una línea jurisprudencial en la que el alcance de aquel dista de resultar preciso. No ha carecido de importancia en la singular evolución de la jurisprudencia constitucional gala, en fin, la existencia de una fuerte presión social y mediática frente al fenómeno europeo, que condujo, de hecho, al Conseil constitutionnel a retrasar la publicación de una muy destacada resolución, de la que se dará cuenta de inmediato, con el fin de que no interfiriera en el proceso electoral entonces abierto ${ }^{10}$.

desde la perspectiva de su implementación jurisdiccional, véase la reciente reflexión de E. Vrannes (2013), «Constitutional Foundations of, and Limitations to, EU Integration in France», European Public Law, 19-3, págs. 525-554 (pág. 531).

9 Así, junto a la mencionada cláusula general, y tras varias reformas sucesivas, incluye el título XV CFr diversas disposiciones, relativas a la orden europea de detención y entrega (artículo 88-2), al derecho de sufragio activo y pasivo de los nacionales de Estados miembro de la Unión en las elecciones locales (artículo 88-3), a las obligaciones de información del Gobierno a las cámaras legislativas en relación con los proyectos de actos normativos en trámite ante las instituciones europeas (artículo 88-4), al referéndum de ratificación de los Tratados que tengan por objeto la adhesión de nuevos Estados miembros (artículo 88-5), a la intervención de las instituciones parlamentarias nacionales en la verificación del respeto del principio de subsidiariedad por los proyectos de actos legislativos europeos (artículo 88-6), y a la posibilidad de oposición de Parlamento y Senado frente a la hipotética modificación de las reglas de adopción de actos de la Unión Europea previstas en el TUE y en el TFUE (artículo 88-7).

10 Se trata de la Decisión n 2004-496 DC, de 10 de junio, Loi pour la confiance dans l'économie numérique, que no se hizo pública sino hasta cinco días más tarde, una vez que ya se habían celebrado las elecciones al Parlamento Europeo. Sobre la cuestión y la recepción periodística de este proceder, así como sobre las explicaciones de los portavoces del Conseil, véase A. Levade (2004), «Le Conseil constitutionnel aux prises 
Durante largo tiempo, el pronunciamiento de referencia en la jurisprudencia constitucional francesa fue la Decisión $\mathrm{n}^{\circ}$ 74-54 DC, de 15 de enero de 1975, Loi relative à linterruption volontaire de grossesse (que sentaría la conocida como doctrina $I V G$ ): en esta resolución, partiendo de una lectura marcadamente restrictiva del marco normativo entonces vigente, el Conseil afirmó que el canon cuya aplicación imponía el artículo 61 CFr para el desarrollo del juicio de validez de la ley nacional se encontraba definido en términos taxativos, de forma que no cabía, pese a la regla del valor supralegal del Tratado Internacional, la integración del mismo en el bloque de constitucionalidad, razón por la que la vulneración de la fuente externa por la disposición legislativa no suponía lesión alguna del artículo $55 \mathrm{CFr}$. Se consagraba, de esta forma, la neta diferenciación del control de constitucionalidad de la ley, que se traduce en un pronunciamiento sobre su validez y que tan solo al Conseil constitutionnel corresponde, frente al control de convencionalidad, que puede derivar en una inaplicación de la ley y que compete en exclusiva a los órganos de la jurisdicción ordinaria. La ausencia de una mención constitucional específica del proceso de integración forzaba a la aplicación de esta doctrina a los supuestos de contravención, por parte de las disposiciones de rango legislativo, del derecho europeo; el Conseil mantendría, sin embargo, su razonamiento incluso una vez reformada la Constitución en el sentido que nos es conocido ${ }^{11}$.

La Decisión no 98-400 DC, de 20 de mayo de 1998, Loi organique déterminant les conditions d'application de l'article 88-3 de la Constitution relatif à l'exercice par les citoyens de l'Union européenne résidant en France, autres que les ressortissants français, du droit de vote et d'élegibilité aux élections municipales, et portant transposition de la directive 94/80/CE du 19 décembre 1994, representa el primero de los momentos esenciales de apertura del Conseil constitutionnel a la integración de fuentes de origen supranacional como parámetro de validez de la ley interna: en ella, el Conseil, con base en la específica mención ex artículo 88-3 CFr de los vínculos de derecho europeo en materia de derecho de sufragio de los ciudadanos de la Unión en las elecciones municipales, declara que dicho mandato constitucional le impone la toma en consideración de las disposiciones de derecho originario y derivado en el enjuiciamiento de la validez de la ley orgánica de desarrollo de aquel precepto (considerando

avec le droit communautaire dérivé», Revue du droit public et de la science politique en France et à l'étranger, 4, págs. 889-911 (pág. 889).

11 Cfr. la Decisión n 98-405 DC, de 29 de diciembre de 1998, Loi de finances pour 1999 , en cuyo considerando $22^{\circ}$ afirma el juez constitucional francés que "no corresponde al Conseil constitutionnel, en tanto actúa al amparo del artículo 61 de la Constitución, examinar la conformidad de la ley a la directiva europea». 
$4^{\circ}$ ) y procede así al análisis de la conformidad de esta con respecto a aquellos, declarando la inexistencia de objeción alguna a su validez en términos constitucionales.

El carácter singular del fundamento constitucional de tal planteamiento impedía, claro está, elevar el razonamiento del Conseil a la categoría de regla general ${ }^{12}$, conclusión abonada por el recordatorio, efectuado por el propio juez constitucional francés, de la doctrina $I V G$ en resoluciones de fechas próximas a la de la analizada ${ }^{13}$. La Decisión $n^{\circ} 2004-496$ DC, de 10 de junio de 2004, Loi pour la confiance dans l'économie numérique, sentaría las bases de una sustancial revisión de la doctrina jurisprudencial del Conseil: así, afirmaría en ella el Alto Tribunal que el artículo 88-1 CFr comporta la caracterización como exigencia constitucional de la obligación de transposición de las directivas europeas en el ordenamiento interno, frente a la que tan solo resulta posible oponer una disposición constitucional expresa en contrario, en ausencia de la cual es competencia exclusiva del Tribunal de Justicia, previa la correspondiente consulta en vía prejudicial, la verificación del respeto por parte de la referida fuente de derecho europeo del sistema de distribución de competencias y de la protección de los derechos fundamentales garantizados por los tratados (considerando $7^{\circ}$ ) y se declararía incompetente para enjuiciar la validez jurídico-constitucional de una ley nacional que se limita a incorporar las disposiciones incondicionales y precisas de una directiva europea (considerando $9^{\circ}$ ). Tal razonamiento sería confirmado, sin quiebra alguna, en diversas resoluciones inmediatamente posteriores ${ }^{14}$.

12 Así lo han destacado, entre otros, A. Levade (2004: 892); J. Roux (2004), «Le Conseil constitutionnel, le droit communautaire dérivé et la Constitution", Revue du droit public et de la science politique en France et à l'étranger, 4, págs. 912-933 (págs. 923-924); O. Tambou (2004), «El Consejo constitucional francés y la relación del Derecho comunitario con la Constitución francesa. A propósito de la importante sentencia del Consejo constitucional francés de 10 de junio (2004-496 DC)», Revista Española de Derecho Europeo, 12, págs. 609-628 (pág. 615) y E. Sales (2005), «La transposition des directives communautaires: une exigence de valeur constitutionnel sous réserve de constitutionnalité», Revue trimestrielle de droit européen, 41-3, págs. 597-621 (pág. 599).

13 La aplicación de la doctrina $I V G$ en estas fechas continuaba sin hacer distingos entre las fuentes de derecho europeo y las de derecho internacional público "ordinario» como parámetro de validez; cfr. las Decisiones n ${ }^{\circ}$ 98-399 DC, de 5 de mayo de 1998, Loi relative à l'entrée et au séjour des étrangers en France et au droit d'asile (considerando $12^{\circ}$ ), $\mathrm{y} \mathrm{n}^{\circ} 98-405$ DC, ya citada (nota 11 ).

14 Véanse las Decisiones no 2004-497 DC, de 1 de julio de 2004, Loi relative aux communications électroniques et aux services de communication audiovisuelle (considerandos 
La Decisión n² 2004-496 DC tuvo en la doctrina francesa el eco que cabía esperar ante un tan destacado replanteamiento del sistema de relaciones interordinamentales por parte de la jurisdicción constitucional nacional. La parquedad del razonamiento daría lugar a lecturas difícilmente conciliables entre sí de la resolución, cuyo carácter innovador, en todo caso, y pese a la invocación del artículo 88-1 CFr por parte del Conseil, no respondía a una transformación directamente perseguida por el Constituyente, sino que se presentaba como el resultado de una interpretación constructiva del Alto Tribunal ${ }^{15}$, como lo demuestran el carácter muy anterior de la reforma constitucional por la que se introdujo la mención de la participación nacional en el proceso de integración europea y la propuesta doctrinal, ya en aquel momento formulada, e inicialmente desatendida, de ampliación del parámetro de constitucionalidad de la ley interna en clave europea ${ }^{16}$.

La correcta comprensión de la resolución exige tener en cuenta que el fundamento último de la reorientación de la jurisprudencia constitucional no era tanto la revisión del parámetro de constitucionalidad de la ley interna cuanto la recepción del principio de primacía ante la entonces proyectada ratificación del Tratado Constitucional Europeo, que incluía por primera vez en el derecho originario una referencia específica al mismo ${ }^{17}$, y, sobre todo, la precisión de las consecuencias que el mismo trae consigo en relación con la delimitación de las competencias del Conseil en el control de validez de las disposiciones legislativas aprobadas para dar cumplimiento a la obligación de transposición ${ }^{18}$. Por lo que hace a la primera

$18^{\circ}$ y $\left.19^{\circ}\right), \mathrm{n}^{\circ} 2004-498 \mathrm{DC}$, de 29 de julio de 2004, Loi relative à la bioéthique (considerandos $4^{\circ}$ y $7^{\circ}$ ), y n ${ }^{\circ} 2004-499$ DC, de 29 de julio de 2004, Loi relative à la protection des persones physiques à l'égard des traitements des données à caractère personnel et modifiant la loi $n^{\circ} 78-15$ du 6 janvier 1978 relative à l'informatique, aux fichiers et aux libertés (considerandos $7^{\circ}$ y $8^{\circ}$ ).

15 En este sentido, véase E. Bruce (2005), «Faut-il intégrer le droit communautaire aux normes de référence du contrôle de constitutionnalité?», Revue française de droit constitutionnel, 63, págs. 539-560 (pág. 542).

16 Cfr. É. Picard (1993), «Vers l'extension du bloc de constitutionnalité au droit européen?», Revue française de droit administratif, págs. 47-54 (esp. págs. 52-53).

17 Habla, en este sentido, de una anticipación del debate acerca de la ratificación de la Constitución Europea O. Tambou (2004: 621 y ss.).

18 Se ha llamado, de hecho, la atención sobre la relevancia cualificada de este último extremo en la resolución del Conseil, razón por la cual se estima insatisfactoria la lectura de la Decisión en términos de primacía de un ordenamiento sobre el otro; en este sentido, M. Gautier y F. Melleray (2004), «Le refus du Conseil constitutionnel d'apprécier la constitutionnalité des dispositions législatives transposant une directive 
cuestión, la caracterización de este vínculo como exigencia constitucional y la afirmación de la existencia de una disposición constitucional expresa en contrario como única excepción oponible a su incumplimiento permiten al Conseil incorporar a su jurisprudencia el principio de primacía sin que, y esto es lo esencial, la superioridad jerárquica del texto constitucional se vea comprometida, razonamiento en el que profundizaría en su Decisión $\mathrm{n}^{\circ}$ 2004-505 DC, de 19 de noviembre, Traité éstablissant une Constitution pour l'Europe, cuya vinculación con la resolución analizada y cuya coincidencia sustancial con la Declaración 1/2004, de 13 de diciembre, de nuestro Tribunal Constitucional, han sido puestas de relieve lúcidamente por la doctrina ${ }^{19}$. Se trata, en suma, de una solución de compromiso cuyo alcance, como observó J. Roux, depende del cristal con que se mire ${ }^{20}$.

communautaire», L'Actualité Juridique - Droit Administratif, págs. 1537-1541 (pág. 1538); J. Dutheil de la Rochère (2005), "Conseil constitutionnel (French Constitutional Court), Decision No. 2004-496 DC of 10 june 2004, Loi por la confiance dans l'économie numérique (e-commerce)", Common Market Law Review, 42-3, págs. 859-869 (pág. 859); y P. Blachèr y G. Protière (2007), «Le Conseil constitutionnel, gardien de la Constitution face aux directives communautaires», Revue française de droit constitutionnel, 69, págs. 123-144 (págs. 142-143).

19 Véanse, en este sentido, L. Azoulai y F. Ronkes Agerbeek (2005), "Conseil constitutionnel (French Constitutional Court), Decision No. 2004-505 DC of 19 November 2004, on the Treaty establishing a Constitution for Europe», Common Market Law Review, 42-3, págs. 871-886 (págs. 877 y 886, nota 69).

Cfr. J. Roux (2004: 915). Así, para algunos autores de la jurisprudencia constitucional francesa no cabe sino deducir la afirmación, por partida doble (dado el fundamento constitucional de la eficacia del ordenamiento europeo en el contexto nacional y la formulación de la reserva frente a la misma), del principio de primacía del texto constitucional sobre el derecho europeo; en este sentido, véase, sobre todo, B. Mathieu (2007), «Les rapports normatifs entre le droit communautaire et le droit national. Bilan et incertitudes reflatifs aux évolutions récentes de la jurisprudence des juges constitutionnel et administratif français», Revue française de droit constitutionnel, 72, págs. 675-693 (pág. 678); igualmente, cfr. P. Cassia (2005), «Le juge administratif, la primauté du droit de l'Union européenne et la Constitution française», Revue française de droit administratif, págs. 465-472 (pág. 466). Para otros, sin embargo, la improbable activación de la reserva y la proclamación del principio de inmunidad constitutional del derecho europeo son muestra de la admisión en el fondo incondicionada de la primacía del ordenamiento de la Unión sobre el texto constitucional francés (en este sentido, véase S. Pinon [2008], «L'effectivité de la primauté du droit communautaire sur la Constitution. Regard sur la jurisprudence récente du Conseil constitutionnel et du Conseil d'État», Revue trimestrielle de droit européen, 44-2, págs. 263-287, passim). 
En lo que a la segunda cuestión respecta, la Decisión n 2004-496 DC permite al Conseil incorporar a su acervo jurisprudencial la denominada doctrina Foto-Frost del Tribunal de Justicia (asunto 314/85), de acuerdo con la cual corresponde tan solo al poder judicial europeo pronunciarse sobre la validez de las disposiciones aprobadas por las instituciones comunitarias. En tanto que enjuiciar la validez jurídico-constitucional de la ley que se limita a incorporar al ordenamiento interno las disposiciones incondicionales y precisas de una Directiva traería consigo un pronunciamiento indirecto sobre la propia fuente del ordenamiento europeo, el Conseil renuncia a llevar a cabo una tal verificación (teoría de la directive écran o del droit communautaire écran), dotando, en definitiva, a la misma de inmunidad constitucional: de esta forma, la activación de la competencia del Alto Tribunal como juez de las leyes de transposición depende ya de la existencia de márgenes de apreciación a favor del legislador nacional, ya de la eventual inobservancia de una disposición constitucional expresa.

Interesa en todo caso destacar ahora, por encima de otro tipo de consideraciones, que la retracción de la competencia del Conseil en el sentido apuntado viene, sin embargo, a partir de la Decisión n ${ }^{\circ} 2004-496$, acompañada de una expansión hasta aquel momento insospechada: así, si, de una parte, el Alto Tribunal declara su incompetencia para controlar el respeto de los vínculos constitucionales por parte de las disposiciones legislativas por las que se transpongan en el ordenamiento nacional las previsiones de una Directiva europea formuladas de manera precisa e incondicional, de otra, la caracterización de la obligación de transposición como exigencia constitucional y la necesaria verificación previa de que la ley estatal se limita a incorporar los mecanismos necesarios para alcanzar el resultado perseguido por la Directiva dotada de efecto directo presuponen una competencia nueva, consistente, precisamente, en controlar el respeto de la segunda por parte de la primera ${ }^{21}$. No es, por consiguiente, sino de forma argumentalmente tangencial como se plantea por primera vez (con alcance general) en la jurisprudencia constitucional francesa la posibilidad de integración en el bloque de constitucionalidad de fuentes de origen europeo.

21 Sobre el carácter ambivalente, desde la perspectiva de las competencias del Conseil constitutionnel, de la doctrina fijada en su Decisión n ${ }^{\circ}$ 2004-496 DC, llaman especialmente la atención J. Roux (2004: 921) y G. Alberton (2005), «De l'indispensable intégration du bloc de conventionnalité au bloc de constitutionnalité?», Revue française de droit administratif, págs. 249-268 (pág. 264; el autor afirma con buen tino que la entera construcción jurisprudencial del Conseil constitutionnel depende de esta nueva competencia de control). En un sentido parcialmente coincidente, en fin, véase P. Blachèr y G. Protière (2007: 127-128). 
Más allá de que la formulación excesivamente sintética de la nueva doctrina constitucional trajera consigo una multiplicidad de interpretaciones en relación con el efectivo reconocimiento del principio de primacía por parte del Conseil constitutionnel, de las que ya se ha dado cuenta ${ }^{22}$, el pronunciamiento reseñado fue objeto de severas críticas doctrinales. Así, desde el rechazo frontal de la línea jurisprudencial por él inaugurada ${ }^{23}$ hasta la formulación de observaciones más concretas, como la relativa a la asimetría que conllevaba la no caracterización de otros vínculos de derecho europeo diferentes de la obligación de transposición como exigencia constitucional ${ }^{24}$, muchas y muy interesantes fueron las líneas de debate doctrinal motivadas por la resolución. Las mismas partieron de dos extremos esenciales de la decisión: de un lado, el carácter problemático de la formulación de la reserva consistente en la existencia de una disposición constitucional expresa en contrario como posible justificación del incumplimiento de la obligación de transposición desde la perspectiva interna, con respecto al cual se produjo un acuerdo doctrinal prácticamente unánime, $y$, de otro, la constatación del efectivo abandono por

22 Cfr. la nota 20.

23 En este sentido, destacan las reflexiones de J. Arrighi de Casanova (2004), «La décision n 2004-496 DC du 10 juin 2004 et la hiérarchie des normes», L'Actualité Juridique - Droit Administratif, págs. 1534-1537 (págs. 1536-1537), que califica de erróneas las conclusiones alcanzadas por el Conseil a partir de una interpretación sistemática del texto constitucional, basada, esencialmente, en que la mención de vínculos específicos del derecho europeo en los artículos 88-2 y ss. CFr impide deducir del artículo 88-1 una interpretación como la fijada por la jurisdicción constitucional francesa. En una línea similar, se mostró perplejidad ante la caracterización como exigencia constitucional de lo que sería, sin embargo, una obligación de origen estrictamente convencional; cfr., en esta línea, B. Genevois (2004), «Le Conseil constitutionnel et le droit communautaire dérivé», Revue française de droit administratif, págs. 651-661 (pág. 653) $y$, en un sentido parcialmente coincidente, por cuanto se refiere a la vulneración tan solo mediata del artículo 88-1 CFr por parte de la ley contraria a la Directiva objeto de transposición, E. Bruce (2005: 549-550).

24 Así, S. Pinon (2008: 280 y 282) se ha referido a la ausencia de distinción alguna entre las diversas fuentes de Derecho europeo en el artículo 88-1 CFr y a la necesidad de interpretar el precepto constitucional citado como fundamento de la imposición al legislador nacional de la obligación de respeto de todos los vínculos derivados de la participación nacional en el proceso de integración. En el mismo sentido, C. Charpy (2009), «Droit constitutionnel et droit communautaire. Le statut constitutionnel du droit communautaire dans la jurisprudence (récente) du Conseil constitutionnel et du Conseil d'État (Contribution à l'étude des rapports des systèmes constitutionnel et communautaire) (I)», Revue française de droit constitutionnel, 79, págs. 621-647 (págs. 622 y 626). 
parte del Conseil de la consideración del artículo 55 CFr como fundamento constitucional del sistema de relaciones entre los ordenamientos nacional y europeo $^{25}$, a partir del cual resultaría obligado analizar la posible rectificación de la doctrina $I V G$ con respecto al concreto problema de la adecuación de la ley nacional a la Directiva objeto de transposición.

En lo que al primer aspecto se refiere, el carácter expreso de la disposición constitucional cuya vulneración pudiera amparar, desde la perspectiva interna, la inobservancia del deber de transposición, parecía exigir, como con acierto se destacó en su momento, una artificial disociación del texto constitucional y de la doctrina del Conseil fijada en su andadura como intérprete supremo del mismo $^{26}$. Por este motivo, en la literatura científica francesa se propusieron lecturas correctoras de la reserva constitucional ${ }^{27}$, que influirían, de hecho, en una revisión de la jurisprudencia del Conseil limitada a esta concreta cuestión, al formularse la reserva ya no con base en la existencia de una disposición constitucional expresa en contrario, sino a partir de la posible lesión de un principio o regla inherentes a la identidad constitucional francesa (Decisión $\mathrm{n}^{\circ}$ 2006-540 DC, de 27 de julio de 2007, Loi relative au droit d'auteur et aux droits voisins dans la société de l'information, considerando $\left.19^{\circ}\right)^{28}$.

25 Por contra, el Conseil d'État ha continuado invocando conjuntamente ambos preceptos constitucionales aun en su jurisprudencia posterior a la Decisión del juez constitucional francés $n^{\circ}$ 2004-496 DC, como destaca E. Vrannes (2013: 532), que afirma no encontrar una explicación convincente de esta divergencia.

26 En este sentido, véanse J. Roux (2004: 928), B. Genevois (2004: 658), M. Gautier y F. Melleray (2004: 1540), J.-P. Kovar (2004), «Commentaire des décisions du Conseil constitutionnel du 10 juin et du $1^{\text {er }}$ juillet 2004: rapport entre le droit communautaire et le droit national», Revue trimestrielle de droit européen, 40-3, págs. 587-597 (pág. 595) y P. Blachèr y G. Protière (2007: 130 y ss.), entre otros.

27 Así, J. Dutheil de la Rochère (2005: 866-867) propondría la comprensión de que la reserva permitiría oponer a la transposición de una Directiva europea en el ordenamiento interno tan solo la inobservancia del estándar de protección iusfundamental constitucionalmente garantizado. En un sentido parcialmente similar, véase E. Sales (2005: 612 y ss.).

28 Dicha innovación sería, no obstante, objeto de una valoración ambivalente en el panorama científico francés: así, hubo por un lado autores que saludaron con favor la reformulación de la reserva constitucional sobre la base de su mayor grado de adecuación al derecho originario europeo, que prevé el principio de respeto de la identidad constitucional de los Estados miembros; en este sentido, véase A. Levade (2007), «Le Palais-Royal aux prises avec la constitutionnalité des actes de transposition des directives communautaires», Revue française de droit administratif, págs. 564-577 (pág. 569); otros, en cambio, vieron en la «nueva» reserva una inválida ampliación de las 
En lo que atañe a la superación de la doctrina $I V G$, la resolución del Conseil apenas citada confirmaría la competencia del Alto Tribunal como garante del respeto por parte del legislador nacional de la obligación de transposición de las directivas y definiría con precisión sus contornos: así, partiendo de una interpretación, en tanto que abierta, radicalmente opuesta a la tradicional, del artículo $61 \mathrm{CFr}$, y una vez rectificada la formulación de la reserva en el sentido apuntado, declara el Conseil que, dado que el control que desarrolla con respecto a la ley es, en el ámbito del recurso de inconstitucionalidad, de carácter exclusivamente preventivo ${ }^{29}$, y dada igualmente su vinculación al plazo de resolución de un mes previsto ex $61 \mathrm{CFr}^{30}$, no puede dirigirse en vía prejudicial ante el Tribunal de Justicia para obtener un pronunciamiento sobre la interpretación de la Directiva en cada caso concernida, motivo por el cual solo puede declarar la invalidez de la ley nacional si la vulneración de la Directiva objeto de transposición es manifiesta, competiendo el análisis en los demás supuestos a los órganos de la jurisdicción ordinaria (considerando $20^{\circ}$ ). Con base en este esquema argumental, el Conseil declararía, en su Decisión $n^{\circ}$ 2006-543, de 30 de noviembre de 2006, Loi relative au secteur de l'énergie, el carácter inconstitucional de diversos preceptos de la ley sometida a su control por vulnerar la Directiva para cuya transposición la misma había sido aprobada, materializando así lo que con acierto no tardaría en calificarse

circunstancias que permitirían oponer obstáculos de derecho constitucional nacional a la obligación de transposición; véase F. Chaltiel (2006), "Nouvelle précision sur les rapports entre le droit constitutionnel et le droit communautaire. La décision du Conseil constitutionnel du 27 juillet 2006 sur la loi relative aux droits d'auteurs», Revue française de droit constitutionnel, 4, págs. 837-847 (pág. 844); e incluso hubo quien la leyó en clave de eliminación radical de toda posible matización al principio de primacía, sobre la base de su difícil activación práctica; cfr., en este sentido, S. Pinon (2008: 265 y ss.).

29 Es decir, el derecho procesal constitucional francés entonces vigente conocía tan solo el recurso previo, sin admitir en ningún caso el control posterior a la entrada en vigor de la Ley (artículo 61 CFr). El 23 de julio de 2008 se aprobaría la Ley de reforma constitucional por la que se introduciría la denominada «cuestión prioritaria de constitucionalidad» (artículo 61-1 CFr), que permite al particular obtener del Conseil un pronunciamiento sobre la validez de la ley nacional desde la perspectiva de la posible lesión de los derechos y libertades constitucionalmente garantizados. Sobre la posibilidad de recurso a este mecanismo procesal para la obtención de la declaración de inconstitucionalidad de una ley por su carácter contrario al ordenamiento europeo en el sistema francés habrá de volverse inmediatamente.

30 Susceptible de reducción al de ocho días en los supuestos de urgencia, previa solicitud del Gobierno. 
de auténtica «revolución jurisprudencial ${ }^{31}$. Ambas resoluciones, leídas conjuntamente con la Decisión n ${ }^{\circ}$ 2006-535 DC, de 30 de marzo de 2006, Loi pour l'égalité des chances, en la que el Conseil descarta su competencia para pronunciarse sobre la validez de una ley desde la perspectiva de su compatibilidad con una directiva europea si no ha sido específicamente adoptada para procurar su transposición en el ordenamiento interno (considerando $28^{\circ}$ ), contribuirían a la clarificación definitiva del estado de la cuestión en la jurisprudencia constitucional francesa, sentando una doctrina aplicada sin solución de continuidad hasta las fechas más recientes ${ }^{32}$.

En conclusión, el Conseil constitutionnel ha introducido, con respecto a la obligación de transposición de las directivas en el ordenamiento jurídico nacional, una muy significativa quiebra de su doctrina tradicional en materia de relaciones entre ordenamientos jurídicos, declarando el carácter de exigencia constitucional de aquella obligación, de la que resulta, de una parte, su incompetencia para controlar la validez de la ley adoptada para incorporar las disposiciones precisas e incondicionales de una directiva, a salvo los supuestos en que la misma conculque una regla o principio inherentes a la identidad constitucional francesa, y, de otra, su competencia para analizar la conformidad de la ley de transposición a la directiva en cada caso controvertida, pudiendo declarar su inconstitucionalidad por no ajustarse manifiestamente a sus prescripciones. Se trata de una doctrina de alcance aún marcadamente restrictivo y en la que, claro está, se evidencian las limitaciones consustanciales a un sistema de control exclusivamente preventivo de la constitucionalidad de

31 Véase B. Mathieu (2007: 684-685). El autor precisa que se trataría, en todo caso, de una transformación sutil, dado que aprecia en la primera de las resoluciones citadas un esfuerzo por parte del Conseil en integrar, junto a la Constitución, las disposiciones de la Directiva como parámetro de control.

32 Véanse, así, las Decisiones del Conseil constitutionnel n 2008-564 DC, de 19 de junio de 2008, Loi relative aux organismes génétiquement modifiés (considerandos $42^{\circ}$ a $45^{\circ}$ ), $\mathrm{n}^{\circ}$ 2010-605 DC, de 12 de mayo de 2010, Loi relative à l'overture à la concurrence et à la regulation du secteur des jeux d'argent et de hasard en ligne (considerandos $17^{\circ}$ a $20^{\circ}$, no obstante el razonamiento recogido en el considerando $16^{\circ}$ de la Sentencia, sobre el que se volverá en el apartado siguiente, de acuerdo con el cual no corresponde al Conseil constitutionnel el examen de la compatibilidad de la ley nacional con los vínculos internacionales y europeos contraídos por la República francesa), n 2011-631 DC, de 9 de junio, Loi relative à l'immigration, à l'intégration et à la nationalité (considerandos $44^{\circ}$ y $\left.45^{\circ}\right), \mathrm{n}^{\circ}$ 2012-659 DC, de 13 de diciembre de 2012, Loi de financement de la sécurité sociale pour 2013 (considerando 56 $6^{\circ}$, n 2015-726 DC, de 29 de diciembre, Loi de finances rectificative pour 2015 (considerandos $4^{\circ}$ y $5^{\circ}$ ), y n ${ }^{\circ} 2015-727$ DC, de 21 de enero de 2016, Loi de modernisation de notre système de santé (considerandos $4^{\circ}$ y $5^{\circ}$ ). 
las leyes ${ }^{33} \mathrm{y}$ fuertemente condicionado por el breve plazo de resolución previsto ex artículo $61 \mathrm{CFr}$. Tal vez sea, al mismo tiempo, producto de un tiento que pueda antojarse (tomando como punto de partida el propio razonamiento de la jurisdicción constitucional francesa) excesivo ${ }^{34}$, pero, personalmente, lo consideramos comprensible ${ }^{35}$ a la vista de la ya por sí sola significativa ruptura que representa frente a la comprensión generalmente imperante del principio de primacía del derecho europeo y, particularmente, con respecto a la jurisprudencia del propio Conseil de hace apenas poco más de una década. En todo caso, desde una perspectiva crítica con las restricciones impuestas por el carácter preventivo del recurso de inconstitucionalidad en el ordenamiento francés, interesa en este momento analizar las posibilidades que ha dejado abiertas la reforma constitucional de 23 de julio de 2008, por la que se ha procedido a la introducción del artículo 61-1 CFr, regulador de un nuevo mecanismo de

33 De hecho, en la doctrina se llegó a proponer en aquel momento, al hilo del análisis de la ampliación del parámetro de validez de la ley nacional desde la perspectiva del derecho europeo y las dificultades derivadas del carácter tan solo preventivo del control de constitucionalidad, la instauración de un control a posteriori como vía más adecuada para la corrección del estado de la cuestión en la jurisprudencia del Conseil; cfr., en este sentido, S. Pinon (2008: 282).

Así, es lo cierto que el requisito de que la ley objeto de fiscalización sea la específicamente orientada a la transposición de la Directiva europea invocada como parámetro carece, en el fondo, de fundamento: nada impide al Conseil, de acuerdo con la razón de ser de su propia jurisprudencia, analizar la posible inobservancia del referido vínculo de derecho europeo con respecto a disposiciones legislativas diferentes de aquella a través de la que se lleva a cabo la transposición, que, de verificarse, podrían dar igualmente lugar a una condena del Tribunal de Justicia por incumplimiento. El Conseil descarta, en definitiva, la posibilidad de comprobar que el legislador se mantiene en el respeto de la Directiva previamente incorporada al ordenamiento nacional, lo cual no viene impuesto por especificidad alguna del marco jurídico que disciplina su actuación y supone la consagración de una lectura significativamente restrictiva de la «exigencia constitucional» analizada. A este respecto, cfr. la sólida crítica de C. Charpy (2009), «Droit constitutionnel et droit communautaire. Le statut constitutionnel du droit communautaire dans la jurisprudence (récente) du Conseil constitutionnel et du Conseil d'État (Contribution à l'étude des rapports de système constitutionnel et communautaire) (II)", Revue française de droit constitutionnel, 80, págs. 795-815 (pág. 800).

35 En este sentido, véase A. Levade (2007: 567): así, si bien la autora destaca que el Conseil ha decidido no explotar todas las posibles líneas de desarrollo del artículo 88-1 CFr, su valoración al respecto es positiva, toda vez que entiende pertinente que el Conseil identifique y delimite con prudencia las diversas facetas que componen la amplia proclamación recogida en el precepto citado. 
control de la constitucionalidad de las leyes, íntimamente conectado con la protección de los derechos fundamentales: la cuestión prioritaria.

\section{LA CUESTIÓN PRIORITARIA DE CONSTITUCIONALIDAD COMO CAUCE PROCESAL PARA LA VERIFICACIÓN DE LA ADECUACIÓN DE LA LEY A LA DIRECTIVA}

La jurisprudencia referida en el epígrafe anterior fue desarrollada en un contexto normativo que desconocía mecanismos procesales diferentes del recurso previo de inconstitucionalidad para el control de la validez de la ley nacional. Consciente de los problemas que la falta de interposición del recurso con anterioridad a la aprobación de la Ley podía traer consigo desde la perspectiva de la efectividad de los derechos fundamentales, el legislador constituyente francés introdujo en julio de 2008 la denominada cuestión prioritaria de constitucionalidad (conocida por sus siglas en francés, $Q P C$ ): esta nueva vía procesal permite al particular que considera que una norma legal ya vigente lesiona alguno de los derechos o libertades reconocidos por el texto constitucional denunciarlo puntualmente ante el juez que esté conociendo del asunto, quien, de entender que la pretensión se encuentra razonablemente fundada, deberá dirigirse con carácter prioritario al Conseil d'État o a la Cour de cassation (en función de que el órgano jurisdiccional remitente se encuentre integrado en el orden contencioso-administrativo o en cualquier otro, respectivamente), a quienes corresponde en último término la decisión en relación con el efectivo planteamiento de la cuestión, que resolverá el Conseil constitutionnel a través del enjuiciamiento de la disposición legislativa controvertida desde la perspectiva del derecho o libertad invocados, pronunciándose sobre su validez.

Por el carácter forzosamente prioritario de la promoción de la cuestión por el juez ordinario, el mecanismo de la QPC planteaba dudas en relación con su compatibilidad con el ordenamiento jurídico europeo, toda vez que la hipótesis, en absoluto irrealizable, de que al órgano jurisdiccional nacional la disposición legislativa objeto de aplicación le planteara dudas en relación con su validez simultáneamente desde las perspectivas constitucional y europea parecía tan solo admitir que se abordara el segundo punto de vista una vez resuelto el primero, lo que a todas luces constituiría un incumplimiento de la consolidada doctrina Simmenthal. Así, de manera muy temprana se dirigió en vía prejudicial la Cour de cassation al Tribunal de Justicia, con el objeto de que este se pronunciara sobre la existencia de una posible tacha en relación con la $Q P C$ desde la perspectiva del ordenamiento jurídico europeo. Y lo hizo de una forma criticada y alabada a un tiempo, por lo que se consideró, de una parte, un manifiesto desconocimiento de la obligación que pesa sobre 
los poderes públicos nacionales de buscar la interpretación más acorde de las disposiciones de derecho interno al ordenamiento europeo ${ }^{36}$, y, de otra, un claro compromiso con la causa comunitaria, que habría evidenciado el que formulara su petición de decisión prejudicial tan pronto como se le presentó la ocasión ${ }^{37}$. Como es sabido, el Tribunal de Justicia resolvió ${ }^{38}$ a través de un pronunciamiento que, por la afabilidad de su tono, recibió la mejor valoración doctrinal ${ }^{39}$, en el que declaró, una vez descartada una interpretación inflexible de su funcionamiento, e introduciendo algunas matizaciones, la compatibilidad del mecanismo de la $Q P C$ con el ordenamiento europeo e invitó, asimismo, al Conseil constitutionnel a abandonar su propia jurisprudencia sobre la imposibilidad fáctica de consulta en vía prejudicial al rechazar que la brevedad de los plazos de resolución constituya una causa válida para abstenerse del cumplimiento de la obligación de colaboración con el poder judicial europeo. El Conseil constitutionnel recogería el guante del Tribunal de Justicia al dirigirle por primera vez una consulta en vía prejudicial en el contexto de una cuestión prioritaria (Decisión n ${ }^{\circ} 2013-314$ P QPC, de 4 de abril de 2013, Jeremy $F$ ), lo que sería lógicamente interpretado como una asimilación correcta del funcionamiento del mecanismo a la luz de las exigencias europeas ${ }^{40}$ que no

36 Así, véase especialmente R. Mehdi (2011), «French Supreme Courts and European Union Law: Between Historical Compromise and Accepted Loyalty», Common Market Law Review, 48-2, págs. 439-473 (pág. 466); para un exhaustivo análisis del parcialmente erróneo punto de partida de la Cour de cassation, cfr. X. Magnon (2010), «La QPC face au droit de l'Union: la brute, les bons et le truand», Revue française de droit constitutionnel, 84, págs. 761-791 (pág. 766).

37 En este sentido, véase especialmente J. Dutheil de la Rochère (2010), «La questione prioritaire de constitutionnalité et le droit européen. La porte étroite», Revue trimestrielle de droit européen, 46-3, págs. 577-187 (págs. 579 y 584).

38 Sentencia de 22 de junio de 2010, asuntos acumulados C-188/10 y C-189/10, Melki y Abdeli.

39 Cfr. D. Sarmiento (2010), «L'arrêt Melki: esquisse d'un dialogue des juges constitutionnels et européens sur toile de fond française», Revue trimestrielle de droit européen, 46-3, págs. 588-598 (esp. págs. 594 y ss.).

40 Cfr., en este sentido, B. Bonnet (2013), «Le paradoxe apparent d'une questione prioritaire de constitutionnalité instrument de l'avènement des rapports de systèmes... Le Conseil constitutionnel et le mandat d'arrêt européen: à propos de la décision $\mathrm{n}^{\circ}$ 2013-314 P QPC du 4 avril 2013, de l'arrêt préjudiciel C-168/13 PPU de la CJUE du 30 mai 2013 et de la décision n² 2013-314 QPC du 14 juin 2013", Revue du droit public et de la science politique en France et à l'étranger, 5, págs. 1229-1257 (págs. 1245-1246), quien destaca la relativización, ínsita en el planteamiento de la cuestión prejudicial, del carácter preliminar de la $Q P C$. 
cabría, no obstante, dadas las especialidades del asunto, entender como una apertura del Conseil a la utilización del instrumento de la cuestión prejudicial en el recurso previo de constitucionalidad ${ }^{41}$.

La exposición anterior nos permite centrar en este momento nuestra atención en una muy relevante sentencia dictada por el Conseil relativa al control de constitucionalidad de la ley nacional conectado con el derecho europeo a través de la cuestión prioritaria. Hallándose en su ánimo influir en el Tribunal de Justicia para que se pronunciase a favor de la validez del mecanismo de la QPC desde la perspectiva jurídica europea, el Conseil constitutionnel trataría de mostrarle, por medio de su Decisión $\mathrm{n}^{\circ}$ 2010-605 DC, de 12 de mayo de 2010, Loi relative à l'overture à la concurrence et à la régulation du secteur des jeux d'argent et de hasard en ligne, una minimización del alcance de sus entonces casi recién asumidas competencias europeas ${ }^{42}$ : así, invocando con carácter general el artículo $55 \mathrm{CFr}$ (lo que no deja de resultar, en sí mismo, una auténtica declaración de intenciones), en lugar de la cláusula constitucional europea del artículo 88-1 CFr (considerando $10^{\circ}$ ), afirmaría que excede de sus atribuciones competenciales la verificación del respeto por parte del legislador nacional de los tratados internacionales, incluidos los que integran el derecho originario europeo (considerando $16^{\circ}$ ). Hasta aquí, el Conseil se mantiene en la línea que ya nos es conocida, en tanto que su competencia en el ámbito del

41 La cuestión prejudicial fue planteada en el contexto de un asunto penal, encontrándose en aquel momento el procesado privado de libertad, razón por la cual el Tribunal de Justicia acordó resolver a través del procedimiento de urgencia, de acuerdo con las disposiciones del artículo 267 TFUE, respondiendo a las dudas del Conseil constitutionnel en menos de dos meses (Sentencia de 30 de mayo de 2013, asunto C-168/13 PPU, Jeremy F.). Ello abonaría el terreno para que, junto a otros aspectos secundarios (como la mención expresa de la materia afectada ex artículo 88-2 CFr), se identificara en la naturaleza del asunto y en la posibilidad de tramitación a través del procedimiento de urgencia el auténtico fundamento del planteamiento de la cuestión por el Conseil; véase, en este sentido, L. Coutron y P.-Y. Gahdoun (2013), "Premier renvoi préjudiciel du Conseil constitutionnel à la Cour de justice de l'Union européene: une innovation aux implications incertaines (à propos de la décision "mandat d'arrêt européen" du Conseil constitutionnel du 4 avril 2013)», Revue du droit public et de la science politique en France et à l'étranger, 5, págs. 1207-1228 (págs. 1219 y ss.).

42 A la Decisión n 2010-605 DC como «contestación» del Conseil constitutionnel a la cuestión prejudicial planteada por la Cour de cassation en el asunto Melki se refiere, entre otros, X. Magnon (2010: 766 y ss.). El propio planteamiento de la cuestión prejudicial ante el Tribunal de Justicia por el Conseil en el asunto Jeremy F. sería leído como un avance cuyo germen se encontraría, de hecho, en la Decisión n 2010-605 DC; en este sentido, véase B. Bonnet (2013: 1246). 
control de convencionalidad alcanza, como se ha analizado supra, tan solo a la verificación del respeto de la obligación de transposición de las directivas, que de hecho se encarga de recordar inmediatamente, mencionando, esta vez sí, el artículo 88-1 CFr (considerandos $17^{\circ}$ a $20^{\circ}$ ). Lo sorprendente en esta Decisión se encuentra en la que se pretende declaración de principio recogida en el considerando $19^{\circ}$, que nos permitimos reproducir literalmente: «el respeto de la exigencia constitucional de transposición de las directivas no afecta a los "derechos y libertades que la Constitución garantiza" y no puede ser invocado, por consiguiente, en el contexto de una cuestión prioritaria de constitucionalidad» (la cursiva es nuestra).

Es clara la intención del Conseil constitutionnel al efectuar una tal proclamación: de lo que se trataba en aquel momento era de convencer al Tribunal de Justicia de que el mecanismo de la $Q P C$ no podría obstaculizar en ningún caso el ejercicio por parte de los órganos jurisdiccionales ordinarios de sus propias competencias como jueces de la legalidad nacional conectada con el derecho europeo, en tanto que el tratamiento de este tipo de problemas se desarrollaría en todo caso al margen de esta nueva vía procesal. Más allá del hecho de que la firme apuesta del Tratado de Lisboa por la protección iusfundamental desmienta esta aseveración, la no matizada cesura que pretende introducir el Conseil constitutionnel entre la defensa de los derechos y libertades y el respeto de los vínculos de derecho europeo por el legislador nacional desconoce el fundamento último de la consolidada doctrina del Tribunal de Justicia relacionada con el efecto directo de la normativa comunitaria, que no es otro, precisamente, que la defensa de la posición del particular frente al poder público nacional: dicho de otro modo, es el ciudadano quien ocupa el centro de esta construcción, motivo por el cual, como es bien sabido, tan solo cabe el reconocimiento de efecto directo de la Directiva no transpuesta a su favor y en contra del Estado incumplidor. Pretender una diferenciación tajante de los ámbitos de la protección de los derechos fundamentales, exclusivo y excluyente de la cuestión prioritaria de constitucionalidad, de una parte, y de la fiscalización de la observancia de las obligaciones impuestas por el ordenamiento europeo, de otra, constituye, en sí mismo, un posicionamiento en contra del acervo jurisprudencial que forma parte de este último.

En todo caso, el Conseil constitutionnel no parece haber profundizado en las consecuencias que se derivarían de esta controvertida afirmación, e incluso parece haber querido rectificar su postura, si bien de forma tímida. Por un lado, como ya sabemos, tramitó una cuestión prioritaria en el marco de un procedimiento penal de inequívocas resonancias comunitarias (Decisión $\mathrm{n}^{\circ}$ 2013-314 P QPC, de 4 de abril de 2013, Jeremy F), aunque frente a esta lectura de la resolución quepa oponer que el marco jurídico involucrado era el de la orden europea de detención y entrega, específicamente mencionado ex 
artículo 88-2 CFr. Sin embargo, ya muy poco después de la Decisión n 2010605 DC, de 12 de mayo de 2010, esta vez en el contexto de una cuestión prioritaria, aplicó nuevamente su propia doctrina sobre los límites de su competencia en la fiscalización de la conformidad a la Constitución de las disposiciones legales que incorporan en el ordenamiento interno las disposiciones precisas e incondicionales de una Directiva: la Decisión n² 2010-79 QPC, de 17 de diciembre de 2010, M. Kamel D. [Transposition d'une directive], es clara al recordar que no le corresponde juzgar, en esos supuestos, la compatibilidad de la ley nacional con el estándar de protección iusfundamental constitucionalmente garantizado (considerando $3^{\circ}$ ). No se trata, en ningún caso, de una rectificación expresa de la doctrina afirmada en la resolución anterior, pero sí de un factor clave para su correcta comprensión, toda vez que la presencia del elemento europeo, en contra de lo que parecía imposible no deducir de su lectura aislada, resulta decisiva para la (no) activación de la competencia del Conseil, que se mantiene, aquí, aparentemente sin matizaciones (pues no añade precisión alguna en contra de su propia facultad de intervención en el control del respeto de la Directiva por la ley interna de transposición a través de la $Q P C$ ), en la línea jurisprudencial inaugurada en 2004 y aplicable inicialmente tan solo en el ámbito del recurso previo de inconstitucionalidad.

Justo es precisar que la cuestión, sin embargo, no puede considerarse aún enteramente resuelta por la jurisdicción constitucional francesa ${ }^{43}$, que, salvo inadvertencia por nuestra parte, no ha vuelto sobre el problema. La posible utilización de la QPC como mecanismo de verificación del respeto de la Directiva europea por la ley nacional de transposición es aún una incógnita en el ordenamiento francés. De esta forma, la apertura del parámetro de constitucionalidad de la ley en clave europea permanece, en aquel sistema, bloqueada por las limitaciones que nos son conocidas, relacionadas con el carácter exclusivamente preventivo del control ordinario de constitucionalidad de las disposiciones legislativas y con el plazo impuesto para su resolución, de una parte, y por la restrictiva lectura que el Conseil mantiene de las implicaciones del artículo 88-1 CFr, de otra. El sistema francés aporta, en todo caso, datos de interés para un análisis de las posibilidades de europeización del canon de validez de las leyes en el ordenamiento español, en la medida en que la doctrina del Conseil en la materia demuestra por sí misma que un mayor compromiso de la jurisdicción constitucional nacional es, en este ámbito, posible.

43 Véase, en este sentido, la reciente reflexión de C. Grewe (2014), "Contrôle de constitutionnalité et contrôle de conventionnalité: à la recherche d'une frontière introuvable», Revue française de droit constitutionnel, 100, págs. 961-970 (pág. 965). 
Sobre ello, no obstante, habrá de volverse en las conclusiones de este trabajo. En este momento procede abordar el estudio del sistema italiano, en el que, como habrá de comprobarse inmediatamente, las limitaciones afirmadas por la Corte costituzionale en relación con su propia competencia como juez de la ley interna desde la perspectiva europea se encuentran directamente conectadas con las exigencias del ordenamiento comunitario, y no con su derecho procesal constitucional.

\section{EL PROBLEMA EN EL SISTEMA ITALIANO: ¿̇LA DISPOSICIÓN EUROPEA COMO CANON DE VALIDEZ DE LA LEY NACIONAL?}

\section{INTRODUCCIÓN. EL COMPLEJO «CAMINO COMUNITARIO»DE LA CORTE COSTITUZIONALE HASTA LA ASIMILACIÓN DE LA DOCTRINA SIMMENTHAL}

La doctrina relativa a la utilización de las normas de la Unión como parámetro de constitucionalidad de las leyes nacionales en Italia es el resultado de un muy largo y no en todas sus fases lineal proceso evolutivo que evidencia la enorme sensibilidad de la Corte costituzionale en la materia y con respecto al cual se destacarán en este trabajo tan solo sus principales hitos jurisprudenciales, por tratarse de un recorrido cuya descripción resulta ciertamente pertinente a los efectos de una exposición de los fundamentos conceptuales del actual estado de la cuestión, pero que no es posible, por razones de espacio, analizar con detenimiento.

El «camino comunitario» de la Corte arranca con el capital asunto Costa c. ENEL: el órgano promotor de la cuestión prejudicial que daría lugar a la justamente célebre resolución del Tribunal de Justicia había consultado, igualmente, a la jurisdicción constitucional italiana sobre la validez de la ley nacional contraria al ordenamiento comunitario. Como es sabido, la respuesta de la Corte costituzionale partiría de presupuestos radicalmente opuestos a los del juez europeo, pues no tomaría en consideración el (entonces aún no proclamado) principio de primacía, sino que afirmaría el rango de mera ley ordinaria de los Tratados fundacionales sobre la base de que ese era el valor del instrumento de ratificación de los mismos en el sistema italiano. Por este motivo, proseguía la Corte, debía excluirse la declaración de inconstitucionalidad de la ley interna que incurría en inobservancia de sus prescripciones por violación mediata del artículo 11 de la Constitución Italiana ${ }^{44}$ (en adelante,

44 Se trata de la cláusula constitucional de apertura del Estado italiano a la participación en procesos de integración supranacional, equivalente de nuestro artículo $93 \mathrm{CE}$, que 
$\mathrm{CI}$ ): el conflicto había de resolverse, pues, con aplicación del principio lex posterior derogat legi priori ${ }^{45}$.

La asimilación de la doctrina del Tribunal de Justicia afirmada en el mismo asunto llegaría de la mano de una resolución igualmente destacada de la Corte costituzionale: la Sentencia 183/1973, de 18 de diciembre, Frontini. En ella, el juez de las leyes incorporaría a su acervo jurisprudencial los extremos más relevantes del régimen jurídico de la fuente reglamentaria de origen comunitario: esta norma penetra, a partir del momento de su publicación en el diario oficial europeo, en los ordenamientos nacionales, sin que la efectividad de tal fenómeno pueda hacerse depender de la adopción de medidas estatales de recepción o ejecución, a salvo los supuestos en que del carácter incompleto de la disposición o de una remisión expresa contenida en la misma a los sistemas jurídicos estatales se derive lo contrario; el análisis de su validez, por otro lado, dado el carácter autónomo y distinto, si bien coordinado de los sistemas comunitario y nacional, no compete a la Corte, excepto en los casos en que la misma pueda incidir en los principios fundamentales del ordenamiento constitucional nacional (teoria dei controlimiti) ${ }^{46}$. Con base en este razonamiento y en el carácter concentrado del sistema italiano de justicia constitucional, que impide al juez ordinario inaplicar por su propia autoridad una norma de rango legal, impondría la Corte al mismo la obligación de planteamiento de la cuestión de inconstitucionalidad frente a la ley contraria al derecho comunitario para, en caso de que procediera su estimación, acordar su expulsión del ordenamiento interno en las Sentencias 232/1975, de 22 de octubre, 205/1976, de 15 de julio, y 163/1977, de 22 de diciembre.

Como es hoy notorio, tampoco este mecanismo de resolución de las antinomias entre las normativas comunitaria y nacional sería admitido por el Tribunal de Justicia: este, por virtud de su Sentencia de 9 de marzo de 1978

dispone lo siguiente: «Italia repudia la guerra como instrumento de ofensa de la libertad de los demás pueblos y como medio de resolución de las controversias internacionales; consiente, en condiciones de reciprocidad con otros Estados, las limitaciones de soberanía necesarias para la configuración de un ordenamiento que asegure la paz y la justicia entre las naciones; promueve y favorece la creación de organizaciones internacionales a tal fin». La simple lectura del precepto evidencia que no se trata de una previsión específicamente ideada para servir de base a la participación en el proceso de integración europea, sino en el sistema de las Naciones Unidas; la Corte, empero, ha identificado en la misma, como habrá de recordarse inmediatamente, el fundamento constitucional de la eficacia del ordenamiento jurídico europeo en el contexto normativo italiano.

Sentencia 14/1964, de 24 de febrero (FJ $6^{\circ}$ ).

FFJJ $7^{\circ}$ y ss. 
(asunto 106/77, Simmenthal), rechazaría que la facultad del órgano jurisdiccional nacional de dejar inmediatamente inaplicada una disposición interna contraria a una norma del ordenamiento jurídico europeo dotada de eficacia directa pueda encontrar obstáculo alguno en la necesidad de culminación previa de un procedimiento de carácter legislativo o constitucional ${ }^{47}$. La Corte costituzionale adecuaría su jurisprudencia a estas nuevas precisiones del Tribunal de Justicia por medio de su Sentencia 170/1984, de 5 de junio, Granital, en la que, declarando expresamente su intención de revisar la doctrina aplicada precedentemente ${ }^{48}$, y siempre sobre la base de una comprensión dualista del sistema de relaciones interordinamentales ${ }^{49}$, afirmaría que la vulneración del derecho comunitario no vicia de nulidad a la ley nacional ${ }^{50}$, competiendo a los órganos de la jurisdicción ordinaria la aplicación de la disposición europea $^{51}$. La Corte declararía, no obstante, la subsistencia de su facultad de fiscalización de la adecuación del ordenamiento interno al europeo en dos supuestos: en primer lugar, en los casos en que las competencias normativas de las (entonces) Comunidades hayan sido ejercitadas por medio de la aprobación de disposiciones no dotadas de efecto directo de acuerdo con la doctrina jurisprudencial del Tribunal de Justicia y no susceptibles, por consiguiente, de aplicación inmediata por parte del juez ordinario ${ }^{52}$; en segundo lugar, en los casos en que la ley nacional "ponga en jaque» la efectiva observancia del sistema introducido por el derecho primario en su conjunto (más allá, por consiguiente, del desconocimiento puntual de una concreta disposición europea) o el núcleo esencial de sus principios ${ }^{53}$.

47 Apartado 24 de la Sentencia.

$48 \mathrm{FJ} 3^{\circ}$.

49 La Corte confirma, así, su visión de los sistemas jurídicos europeo y nacional como dos ordenamientos autónomos y distintos, si bien coordinados, e identifica en el artículo 11 CI el fundamento de la inmediata aplicabilidad de las disposiciones comunitarias en el contexto interno $\left(\mathrm{FJ} 4^{\circ}\right)$.

50 FJ $5^{\circ}$.

$51 \mathrm{FJ} 6^{\circ}$.

52 Ante una norma comunitaria de estas características, prosigue la Corte, la ley nacional conserva el valor y la eficacia que le son propios y, por consiguiente, resulta aplicable a la misma el régimen jurídico común a toda disposición legislativa interna, inclusivo del control ordinario de constitucionalidad $\left(\mathrm{FJ} 5^{\circ}\right)$.

FJ $7^{\circ}$. 


\section{ULTERIORES DESARROLLOS DE LA JURISPRUDENCIA DE LA CORTE COSTITUZIONALE: LA EXPLORACIÓN DE LOS INTERSTICIOS DE LA DOCTRINA GRANITAL}

La jurisprudencia constitucional italiana sucesiva profundizaría, en lo que aquí interesa, en la línea de la compatibilización de la facultad de inaplicación de la ley nacional contraria por parte del juez ordinario y de la potestad de la Corte de verificación del respeto de los vínculos de derecho comunitario europeo. Inicialmente circunscrita a los términos literales de la Sentencia Granital, limitando consiguientemente su intervención a los supuestos de denuncia por el órgano jurisdiccional remitente de la cuestión de inconstitucionalidad de vulneraciones frontales de los principios nucleares del sistema de los Tratados $^{54}$ o de disposiciones comunitarias carentes de efecto directo ${ }^{55}$, en el décimo aniversario de aquella resolución dictaría la Corte un nuevo pronunciamiento crucial: la Sentencia 384/1994, de 7-10 de noviembre, por virtud de la que declaró la inconstitucionalidad, en el contexto de un recurso previo, de una ley regional por su carácter contrario a un Reglamento comunitario.

La resolución daría lugar a múltiples comentarios doctrinales que, pese a suscribir en sus líneas maestras el razonamiento de la Corte costituzionale, considerado plenamente coherente con la doctrina Granita $^{56}$, no dejarían de evidenciar sus debilidades. Así, se criticaría, de una parte, la asimetría de los remedios jurídicos aplicables a los supuestos de contravención del ordenamien-

54 Cfr. la Sentencia 286/1986, de 19 de diciembre.

55 En este concreto ámbito y en esta etapa de la jurisprudencia constitucional italiana, véanse las Sentencias 306/1992 y 307/1992, de 18 de junio-1 de julio.

56 En este sentido, vid. F. Sorrentino (1994), "Una svolta apparente nel 'cammino comunitario' della Corte: l'impugnativa statale delle leggi regionali per contrasto con il diritto comunitario», Giurisprudenza costituzionale, págs. 3456-3458 (págs. 34563457); F. Bientinesi (1994), "Regolamenti comunitari e controllo preventivo delle leggi regionali», Giurisprudenza costituzionale, págs. 3458-3466 (pág. 3463); F. Donati (1994), «I rapporti tra diritto interno e diritto comunitario: problemi e prospettive alla luce di una recente sentenza della Corte costituzionale», Giurisprudenza costituzionale, págs. 3467-3477 (págs. 3468, 3470 y 3476); P. Giangaspero (1994), «Note sull'utilizzazione del diritto comunitario immediatamente applicabile nel giudizio di legittimità costituzionale in via principale», Giurisprudenza costituzionale, págs. 34823493 (págs. 3490 y ss.); R. Bin (1996), «All'ombra della 'La Pergola'. L'impugnazione in via principale delle leggi contrarie a norme comunitarie», Il diritto dell'Unione europea, págs. 271-281 (pág. 274) y A. La Pergola (1999), "Costituzione e integrazione europea: il contributo della giurisprudenza costituzionale», en AA. VV. Studi in onore di Leopoldo Elia, I, Milano: Giuffrè Editore, págs. 815-846 (págs. 833 y ss.). 
to comunitario por parte del legislador nacional: la jurisdicción constitucional italiana habría consagrado el otorgamiento de un tratamiento diferenciado a la norma primaria interna contraria al derecho europeo en función del cauce procesal en que se esgrimiera tal circunstancia, privilegiando un aspecto adjetivo sobre el dato material de la inobservancia de dicho vínculo, cuando la solución habría de ser, más bien, la opuesta ${ }^{57}$. De otra, se pondría de manifiesto la arbitrariedad de la postura de la Corte, que declararía la procedencia de la declaración de inconstitucionalidad por vulneración del ordenamiento comunitario tan solo con respecto a las leyes regionales ${ }^{58}$, en consonancia con una resolución inmediatamente anterior (Sentencia 115/1993, de 24-26 de marzo) en la que había rechazado la fiscalización de una norma primaria estatal recurrida por una región con base en el desconocimiento de las disposiciones de aquel sistema ${ }^{59}$. De esta última crítica se haría eco la Corte en su Sentencia 94/1995, de 20-30 de marzo, en la que, nuevamente en el contexto de la impugnación directa de una ley regional, declararía la idoneidad del referido mecanismo para verificar, igualmente, la adecuación de la fuente primaria estatal al ordenamiento comunitario $^{60}$, rectificación con la que terminaría de delimitar, antes de la reforma constitucional de 2001, los contornos de su propia jurisprudencia en la materia y que sería objeto de una acogida doctrinal lógicamente favorable ${ }^{61}$.

La Corte ampliaría, así, sus posibilidades de intervención como garante del cumplimiento del derecho europeo por parte del legislador nacional: basando (nuevamente) su entero razonamiento en la no irrogación de perjuicio alguno a la competencia comunitaria del juez ordinario en los supuestos de promoción de un recurso directo de inconstitucionalidad frente a la norma legal, extendería a mediados de la década de los noventa sus facultades de fiscalización más allá de los ámbitos expresamente mencionados en su Sentencia 170/1984. De esta forma, la desactivación de sus competencias de fiscalización exige el cumplimiento cumulativo de dos requisitos: que la disposición de derecho europeo potencialmente vulnerada sea susceptible de desplegar

57 Particular interés revisten, al respecto, las reflexiones críticas de A. Ruggeri (1995), "Le leggi regionali contrarie a norme comunitarie autoapplicative al bivio fra 'non applicazione' e 'incostituzionalità'», Rivista italiana di diritto pubblico comunitario, págs. 469-489 (pág. 472). Véanse, además, F. Bientinesi (1994: 3461), E. Gianfrancesco (1994: 3481) y R. Bin (1996: 274).

58 FJ $2^{\circ}$ de la Sentencia.

59 Cfr. F. Sorrentino (1994: 3457), F. Donati (1994: 3476), E. Gianfrancesco (1994: 3481), P. Giangaspero (1994: 3488-3489), A. Ruggeri (1995: 478-479) y R. Bin (1996: 275).

60 FJ $2^{\circ}$ de la Sentencia.

61 Por todos, cfr. R. Bin (1996: 277). 
efecto directo, de acuerdo con la consolidada doctrina del Tribunal de Justicia en la materia, y que el problema no haya sido sometido a su análisis por medio de la impugnación en vía principal de la norma nacional controvertida, sino a través de una cuestión incidental en el seno de un procedimiento judicial en el que se ponga de manifiesto la antinomia.

Sobre esta visión del problema habrá de volverse en las conclusiones de este trabajo; resta aún, sin embargo, el análisis previo de las implicaciones de la reforma constitucional de 2001 en la jurisprudencia italiana relativa a la validez de la norma legal nacional contraria al derecho de la Unión.

\section{LA REFORMA DEL ARTÍCULO $117.1 \mathrm{CI}$ Y LA DEFINITIVA CONSAGRACIÓN DEL ARTÍCULO $11 \mathrm{CI}$ COMO FUNDAMENTO DE LAS COMPETENCIAS DE LA CORTE}

Al hilo de una profunda revisión del título V de la Parte II de la Constitución italiana, incidente sobre el sistema de distribución de competencias entre los diversos niveles de gobierno, se abordó la cuestión de la mención, largamente debatida, de los vínculos de origen supraestatal que pesan sobre los poderes internos. La inicial pretensión de incorporar al texto constitucional italiano un precepto de vocación similar a la del Europa-Artikel alemán (artículo $23 \mathrm{GG}$ ), esto es, una previsión exhaustiva de los aspectos materiales y procedimentales relativos a la participación estatal en el proceso de integración, llamada, por su condición de tal, a desplazar en este ámbito a la cláusula general de apertura del artículo $11 \mathrm{CI}$, no llegaría, sin embargo, a prosperar: de esta forma, el «nuevo» artículo 117.1 CI tan solo dispone que «la potestad legislativa es ejercitada por el Estado y las Regiones con respeto de la Constitución, así como de los vínculos que derivan del ordenamiento comunitario y de las obligaciones internacionales».

El tiento, compatible aquí con la firmeza, con el que la Corte costituzionale había tratado de definir sus competencias en materia de derecho europeo y lo lacónico de la nueva prescripción, por contraste con la ambición del propósito inicialmente manifestado en sede política ${ }^{62}$, no impidieron la defensa de interpretaciones radicalmente contrarias a la doctrina Simmenthal: así, en lo que a la vinculación del legislador nacional al ordenamiento comunitario

62 Un muy exhaustivo análisis de la cuestión puede encontrarse en C. Curti Gialdino (1998), «Revisione costituzionale ed Unione europea: prime osservazioni sul progetto della Commissione parlamentare per le riforme costituzionali», en AAVV, Scritti in onore di Giuseppe Federico Mancini, I: Diritto dell'Unione europea, Milano: Giuffrè Editore, págs. 125-225, passim. 
respecta, se abogó, más o menos abiertamente, por la comprensión de que una tal previsión había de ser leída como una atribución del carácter de parámetro de validez jurídico-constitucional de la ley interna al derecho europeo en su conjunto ${ }^{63}$, llegando incluso a proponerse la oposición, frente a la jurisprudencia del Tribunal de Justicia, del principio de unidad de la jurisdicción constitucional como valor fundamental del ordenamiento nacional, caracterización, de acuerdo con la postura tradicional de la Corte, que ampararía la inobservancia de la referida construcción (teoria dei controlimiti, afirmada, como se ha visto supra, a partir de la Sentencia 183/1973, Frontini) ${ }^{64}$.

Ciertamente, la interpretación del alcance del «nuevo» artículo $117.1 \mathrm{CI}$ no era, en los momentos inmediatamente posteriores a la reforma de 2001, tarea fácil. Debiendo sin duda admitirse que la mera consagración en el más alto nivel normativo interno del equilibrio alcanzado en materia de relaciones interordinamentales constituía, per se, un elemento innovador ${ }^{65}$, el contexto en que la revisión se había producido y el ejemplo de otros sistemas, que, ya a raíz de la entrada en vigor del Tratado de Maastricht, habían introducido previsiones constitucionales dotadas de una muy destacada relevancia no solo dogmática, sino también práctica ${ }^{66}$, constituían inequívocos factores de promoción de una lectura maximalista del referido precepto. De esta forma, se defendería inicialmente que el artículo 117.1 CI estaba llamado no solo a servir de fundamento a una revisión de la tradicional comprensión dualista de la Corte en materia de relaciones entre sistemas jurídicos ${ }^{67}$, sino incluso a desplazar al artículo $11 \mathrm{CI}$ como base constitucional de la jurisprudencia

63 En este sentido, véase L. Torchia (2001), «I vincoli derivanti dall'ordinamento comunitario nel nuovo Titolo V della Costituzione», Le Regioni, págs. 1203-1211 (pág. 1206); igualmente, con una notable dosis de ambigüedad, véase G. Serges (2006), "Art. 117, $1^{\circ}$ co.», en R. Bifulco, A. Celotto y M. Olivetti (eds.), Commentario alla Costituzione, III: Artt. 101-139, Disposizioni transitorie e finali, Torino: UTET Giuridica, págs. 2213-2226 (pág. 2225).

64 Cfr. S. Catalano (2006), «L'incidenza del nuovo articolo 117, comma 1, Cost. sui rapporti fra norme interne e norme comunitarie», en N. Zanon (ed.), Le Corti dell'integrazione europea e la Corte costituzionale italiana. Avvicinamenti, dialoghi, dissonanze, Napoli: Edizione Scientifiche Italiane, págs. 129-151 (págs. 144-146).

65 En este sentido, véase F. Paterniti (2004), «La riforma dell'art. 117, comma 1, Cost. e le nuove prospettive nei rapporti tra ordinamento giuridico nazionale e Unione europea», Giurisprudenza costituzionale, págs. 2101-2128 (pág. 2105).

66 Piénsese en los ya citados casos alemán (artículo 23 GG) y francés (artículos 88-1 y ss. CFr).

67 En este sentido, cfr. F. Paterniti (2004: 2103); y R. Calvano (2005), «La Corte costituzionale 'fa i conti' per la prima volta con il nuovo art. 117 comma 1 Cost. Una svista 
que nos es conocida; conclusión, esta última, cuando menos implícitamente favorecida por la propia Corte en sus Sentencias 406/2005, de 24 de octubre, y 129/2006, de 23 de marzo, que fueron, comprensiblemente, leídas como una clara manifestación del propósito de la jurisdicción constitucional italiana de situar al «nuevo» artículo $117.1 \mathrm{CI}$ en el centro de su jurisprudencia ${ }^{68}$.

La Corte no tardaría, sin embargo, en clarificar el estado de la cuestión tras la reforma constitucional de 2001. Así, por medio de las denominadas «sentencias gemelas» 348 y 349/2007, ambas de 22 de octubre, en las que reconoció el carácter de parámetro de constitucionalidad de la ley nacional al Convenio Europeo de Derechos Humanos, introdujo una importante diferenciación: si bien al CEDH, ex artículo 117.1 CI, debía atribuírsele el carácter de norma interposta, por su condición de tal ubicada en un nivel jerárquico intermedio entre la Constitución y la ley interna, lo que lo convertía, igualmente, en potencial objeto de un análisis de conformidad al conjunto de disposiciones de la primera, la misma conclusión no era predicable del derecho de la Unión, respecto al cual el canon aplicable a un hipotético control se encontraría limitado a los principios y valores fundamentales del ordenamiento (teoria dei controlimiti), identificando como base normativa de su singularidad, precisamente, al artículo $11 \mathrm{CI}^{69}$. La cuestión, lógicamente, no dejaría de conocer una amplia resonancia en la literatura científica italiana ${ }^{70}$.

o una svolta monista della giurisprudenza costituzionale sulle "questioni" comunitarie?», Giurisprudenza costituzionale, págs. 4436-4443 (pág. 4439).

La primera de las sentencias referidas mencionaba, de hecho, tan solo al artículo 117.1 CI como base de la apertura del parámetro de constitucionalidad de la ley nacional en clave europea, mientras que la segunda se valía del mismo apoyándose, igualmente, en el artículo 11 CI. Sobre esta cuestión, véanse R. Calvano (2005: 4441-4442) y G. Serges (2006: 2222). En contra de una tal lectura del artículo 117.1 CI y de las sentencias referidas, con cita del Auto 454/2006, de 13 de diciembre, que afirma el carácter fundado sobre el artículo $11 \mathrm{CI}$ de la jurisprudencia constitucional en la materia, cfr. R. Mastroianni (2006), "Le norme comunitarie non direttamente efficaci costituiscono parametro di costituzionalità delle leggi interne?», Giurisprudenza costituzionale, págs. 3520-3533 (págs. 3531-3533); en la misma línea de este autor, véanse F. Sorrentino (2006), «Il diritto europeo nella giurisprudenza della Corte costituzionale: problemi e prospettive», Quaderni regionali, págs. 625-639 (pág. 632) y A. Pace (2007), «La sentenza Granital, ventitré anni dopo», Studi sull’integrazione europea, págs. $451-467$ (pág. 465). Cfr. el FJ $4^{\circ}$ de la Sentencia 348/2007 y el FJ 6º.1 de la Sentencia 349/2007.

70 En concreto, sobre el tratamiento diferenciado de CEDH y derecho de la Unión y la correlativa minimización de efectos de la mención de los vínculos derivados del ordenamiento comunitario ex artículo 117.1 CI, véanse C. Pinelli (2007), «Sul trattamento giurisdizionale della CEDU e delle leggi con essa confliggenti», Giurisprudenza costituzionale, págs. 
Los sucesivos pronunciamientos de la Corte costituzionale confirmarían, en líneas generales, esta nueva orientación. Así, si bien la Sentencia 28/2010, de 25 de enero, en la que se declara por vez primera la inconstitucionalidad de un decreto legislativo estatal por vulneración de una disposición europea carente de efecto directo, además de introducir la destacada proclamación del carácter «vinculante y superior» del derecho de la Unión con respecto al ordenamiento interno $^{71}$, mantiene aún la referencia conjunta a ambas previsiones constitucionales $^{72}$, la Sentencia 227/2010, de 21 de junio, con ánimo casi pedagógico, se alinea plenamente con las resoluciones apenas mencionadas, diferenciando netamente el ámbito de aplicación del artículo $11 \mathrm{CI}$, en el que se encuentra el fundamento de la jurisprudencia objeto de estudio, frente al del artículo 117.1 $\mathrm{CI}$, confirmación de uno solo de los aspectos relevantes de la doctrina aplicable en materia de relaciones entre ordenamientos ${ }^{73}$. En esta etapa destacaría, igualmente, el primer planteamiento por parte de la Corte de una cuestión prejudicial al Tribunal de Justicia, promovida, a diferencia del caso español, en el contexto de un recurso directo de inconstitucionalidad (Auto 103/2008, de 13 de febrero), sin duda consolidación definitiva de su papel de garante del ordenamiento jurídico europeo en el ámbito del control jurisdiccional de las normas.

La jurisprudencia de la Corte dictada con posterioridad a la reforma del artículo $117.1 \mathrm{CI}$ ha estado caracterizada, pues, por una sustancial continui-

3518-3525 (págs. 3521-3522); A. Moscarini (2007), «Indennità di espropriazione e valore di mercato del bene: un passo avanti (ed uno indietro) della Consulta nella costruzione del patrimonio costituzionale europeo», Giurisprudenza costituzionale, págs. 3525-3534 (págs. 3528-3529); M. Cartabia (2007), «Le sentenze 'gemelle': diritti fondamentali, fonti, giudici», Giurisprudenza costituzionale, págs. 3564-3574 (pág. 3570); A. Guazzarotti (2007), «La Corte e la CEDU: il problematico confronto di standard di tutela alla luce dell'art. 117, comma 1, Cost.», Giurisprudenza costituzionale, págs. 3574-3579 (pág. 3578) y R. Mastroianni (2009), «L’ordinamento giuridico nazionale nei rapporti con la regole comunitarie e dell'Unione europea. La posizione della Corte costituzionale italiana», Diritto comunitario e degli scambi internazionali, págs. $437-465$ (págs. 439 y 443).

71 Declaración recibida con aplauso por la doctrina, que identificaría en la misma una admisión explícita de la doctrina monista, ya no solo aplicada materialmente; cfr., en este sentido, A. Celotto (2010), «Venisti tandem! La Corte, finalmente, ammette che le norme comunitarie sono 'cogenti e sovraordinate'», Giurisprudenza costituzionale, págs. 382-385 (págs. 384-385).

72 Ambos extremos se encuentran recogidos en el FJ $7^{\circ}$ de la Sentencia.

73 FJ 70 de la Sentencia. Este extremo ha sido lúcidamente puesto de relieve por R. Calvano (2010), "Una nuova (ed ottima) decisione in tema di mandato d'arresto europeo ed una vecchia obiezione», Giurisprudenza costituzionale, págs. 2623-2630 (págs. 2625-2626). 
dad, desde una perspectiva material, con respecto a la lectura de la Sentencia Granital desarrollada a partir de mediados de los años noventa, así como por la precisión del alcance de la referida revisión constitucional tanto en el concreto ámbito objeto de análisis en este estudio como en materia de articulación de las disposiciones de derecho nacional con las provenientes de sistemas jurídicos de origen supraestatal diferentes de la Unión Europea. ¿Es esta última una puntualización limitada al plano teórico y/o, en todo caso, al nacional italiano? Entendemos que no: dejando a un lado la cuestión del diverso alcance de la posibilidad de fiscalización por la Corte de la fuente convencional, de una parte, y del derecho de la Unión, de otra, los desarrollos que jurisprudencia y doctrina italianas han conocido en este punto evidencian, a ojos del jurista espańol, el carácter hasta cierto punto limitado de la relevancia, con respecto a la cuestión específicamente analizada en este trabajo, de la proclamación constitucional de la sujeción del legislador interno a los vínculos contraídos en el contexto comunitario europeo. Sobre estos aspectos habrá de volverse inmediatamente; conviene, no obstante, dar antes breve noticia de un muy reciente (y controvertido) pronunciamiento de la Corte costituzionale.

\section{LA RECIENTE SENTENCIA 133/2016, DE 19 DE ABRIL: ¿UN PASO ATRÁS?}

Por virtud de la Sentencia 133/2016, de 19 de abril, la Corte resuelve las cuestiones de inconstitucionalidad promovidas por los Tribunales Administrativos de las regiones de Lombardía, Emilia-Romaña y Lacio, así como por el Consejo de Estado, en relación con diversos preceptos del Decreto Ley 90/2014, de 24 de junio, de medidas urgentes para la simplificación y la transparencia administrativas y para la eficiencia de las oficinas judiciales, convalidado por Ley 114/2014, de 11 de agosto. En particular, el Tribunal Administrativo de la región Emilia-Romaña había planteado sus dudas en relación con el efectivo respeto por parte de la nueva normativa de los artículos 1, 2 y 6.1 de la Directiva 2000/78/CE del Consejo, de 27 de noviembre de 2000, relativa al establecimiento de un marco general para la igualdad de trato en el empleo y la ocupación, de acuerdo con la interpretación dada a los mismos por Sentencia del Tribunal de Justicia de 6 de noviembre de 2012 (asunto C-286/12, Comisión c. Hungría), basando su consulta en la posible vulneración mediata del artículo 117.1 CI. Al resolver sobre esta cuestión, la Corte costituzionale analiza la doctrina afirmada por el Tribunal de Justicia en la sentencia apenas mencionada, rechazando la identificación, en que se basa el órgano jurisdiccional a quo, de los ámbitos de aplicación de las normativas húngara e italiana y declarando la inexistencia de una vulneración del derecho 
de la Unión Europea, con la consiguiente desestimación de la pretendida lesión del artículo $117.1 \mathrm{CI}^{74}$.

La resolución, en este específico punto, y por varios motivos, a la luz de la jurisprudencia analizada en las páginas anteriores, no puede dejar de sorprender. Tratándose la materia afectada (discriminación por razón de la edad en las relaciones laborales) de un campo en el que el Tribunal de Justicia ha tradicionalmente partido de la directa eficacia de las disposiciones previstas en la Directiva invocada por el juez remitente de la cuestión de inconstitucionalidad, es claro que correspondía al mismo la resolución del asunto por medio de la inaplicación de la norma nacional contraria, previa consulta en vía prejudicial, en su caso, al Tribunal de Luxemburgo. No habiendo aquel actuado así, la Corte costituzionale debería haber declarado la inadmisibilidad de la cuestión en lo que a este extremo respecta por su incompetencia para resolver, acordando la remisión del asunto al TAR de Emilia-Romaña. Al no proceder de este modo, la Corte parece acometer un retorno a la era pre-Granital ${ }^{5}$, con manifiesta inobservancia de la doctrina Simmenthal, de cuya asimilación por el juez constitucional italiano, a la vista de los desarrollos que su jurisprudencia ha conocido en los últimos treinta años, no parecía, en principio, poder dudarse. La misma perplejidad suscita la naturalidad con que la Corte analiza el problema desde la exclusiva perspectiva del artículo $117.1 \mathrm{CI}$, lo que representa una clara ruptura con respecto a las precisiones efectuadas en las sentencias de que se ha dado cuenta en el epígrafe anterior ${ }^{76}$. Solo cabe esperar, en fin, que se trate de un pronunciamiento aislado en la dilatada trayectoria europea de la Corte, cuya inconsistente doctrina se apresuren a desmentir resoluciones mejor fundadas e incardinadas en la línea tradicional del juez constitucional italiano.

\section{CONCLUSIONES. BREVE EXCURSO SOBRE LA PERTINENCIA DE LA APERTURA DEL CONTROL DE CONSTITUCIONALIDAD DE LA LEY NACIONAL EN CLAVE EUROPEA}

La exposición anterior evidencia, en nuestra opinión, lo discutible de la doctrina del Tribunal Constitucional español, basada, como se ha recordado

\footnotetext{
74 FJ $4^{\circ} .2$ de la Sentencia.

75 En este sentido, véase R. Mastroianni (2016), «La Corte costituzionale e il giudizio incidentale sulle leggi 'anticomunitarie': il passo del gambero?», Osservatorio europeo (recuperado por última vez el 1 de febrero de 2017 del sitio web: http://www. dirittounioneeuropea.eu/index.php?option=com_content $\& v i e w=\operatorname{article} \& i d=436: 1 a-$ corte-costituzionale-e-il-giudizio-incidentale-sulle-leggi-anticomunitarie-il-passo-delgambero\&catid=77: osservatorio\&lang=it\&Itemid=141), págs. 1-7 (esp. págs. 2 y 4).

76 Cfr. R. Mastroianni (2016: 6).
} 
supra, en la consideración del conflicto entre ley nacional y derecho de la Unión Europea como una cuestión de mera legalidad ordinaria, carente de relevancia en los procedimientos de control ya incidental, ya principal, de la validez de la norma primaria. Conseil constitutionnel y Corte costituzionale han acometido la elaboración de sendos acervos jurisprudenciales en la materia que, si bien basados en presupuestos diferentes y de alcance muy desigual, ponen de manifiesto la posibilidad de una intervención fiscalizadora por parte de la jurisdicción constitucional nacional con respecto a la efectiva observancia de los vínculos asumidos por el legislador interno en el contexto comunitario.

En consonancia con estas destacadas construcciones, muy recientemente se ha abordado, desde diversas perspectivas, el estudio crítico de la doctrina Simmenthal y, sobre todo, de la casi general comprensión de la misma por parte de los operadores jurídicos nacionales. Si bien es cierto que algunas de las líneas de razonamiento en la materia resultan de imposible cohonestación con las bases del modelo de control jurisdiccional de las normas vigente en nuestro sistema, que anuda a la inconstitucionalidad de la ley la sanción de nulidad ${ }^{77}$, otras lecturas del problema encuentran, en cambio, incontrovertible acomodo en nuestro derecho y se muestran, al mismo tiempo, plenamente respetuosas con la doctrina del Tribunal de Justicia. Destacan, en este sentido, las reflexiones de D. Piqani, que, pese a interpretar que Simmenthal representa una firme apuesta por la no caracterización del conflicto como problema de constitucionalidad, defiende certeramente que el principio de colaboración leal y el correlativo deber de adopción de las medidas necesarias para garantizar el cumplimiento de las políticas europeas imponen la aplicación de las técnicas con que los ordenamientos de los Estados miembros dotan a cada una de las instituciones nacionales, mencionando expresamente, a estos efectos, la declaración de invalidez de la norma legal por parte de la jurisdicción constitucional ${ }^{78}$. Se trata de una conclusión a la que no podemos

77 En este sentido, no puede tomarse en consideración la propuesta de S.-P. Hwang (2016), «Anwendungsvorrang statt Geltungsvorrang? Normlogische und institutionelle Überlegungen zum Vorrang des Unionsrechts», EuropaRecht, págs. 355-372 (pág. 364), de superación de la doctrina alemana del Anwendungsvorrang basada en la disociación kelseniana de la ilegalidad frente a la nulidad de la norma jurídica, dados la inequivocidad de los términos del artículo 39.1 LOTC y el carácter excepcional de la corrección jurisprudencial de la aplicación de la sanción de nulidad con eficacia ex tunc a la ley inconstitucional.

78 Cfr. D. Piqani (2016), «The Simmenthal revolution revisited: what role for constitutional Courts?», en B. De Witte, J. A. Mayoral, U. Jaremba, M. Wind y K. Podstawa (eds.), National Courts and EU Law. New Issues, Theories and Methods, Cheltenham/ Northampton: Edward Elgar Publishing, págs. 26-48 (págs. 34-35 y 39). Una con- 
sino adherirnos sobre la base de la exclusiva mención en la tantas veces citada Sentencia Simmenthal de las disposiciones europeas dotadas de eficacia directa como fundamento de la derogación de la competencia de los Tribunales Constitucionales nacionales en la materia ${ }^{79}$ y de la fuerte potencialidad expansiva que el Tribunal de Justicia ha reconocido tradicionalmente al principio de colaboración leal. Parece incontestable, desde esta perspectiva, que, cuando menos en el contexto de un recurso directo, el análisis de la compatibilidad de la ley interna con el derecho de la Unión por la jurisdicción constitucional no perjudica la competencia del juez ordinario ${ }^{80}$, como prueba el hecho de que el mismo tipo de impugnación sea admitido con toda naturalidad respecto a las normas reglamentarias ${ }^{81}$, y que en esa dirección habrá de avanzar nuestro Tri-

clusión similar, aunque de signo no imperativo, sino tan solo posibilista, con idéntico apoyo en el principio de colaboración leal, fue hace ya tiempo defendida entre nosotros por P. Requejo Rodríguez (1997), Bloque constitucional y bloque de la constitucionalidad, Oviedo: Universidad de Oviedo, Servicio de Publicaciones, pág. 110, si bien la autora considera innecesaria la involucración de la jurisdicción constitucional sobre la base de la pervivencia de la aplicabilidad de la norma legal nacional a los supuestos ajenos al contexto europeo: el fallo comportaría, de ser estimatorio, la mera inaplicación de la ley, solución que ya se alcanzaría de acuerdo con el estado actual de la cuestión; frente a este argumento entendemos oponible la mejora, desde la perspectiva del principio de seguridad jurídica, que el pronunciamiento del Tribunal Constitucional, por su condición de tal dotado de eficacia erga omnes, trae inequívocamente consigo.

79 Como se ha visto supra (III.2), este es, precisamente, uno de los fundamentos conceptuales basilares de la Sentencia Granital de la Corte costituzionale italiana y de sus posteriores desarrollos.

81 Como es sabido, el Tribunal Supremo ha ampliado su competencia de control de la validez de las disposiciones de carácter general desde la perspectiva de su conformidad al derecho de la Unión Europea; entre las resoluciones más destacadas en los últimos tiempos que declaran la nulidad de una norma reglamentaria por su contravención, cfr. la Sentencia de 1 de junio de 2010 (recurso contencioso-administrativo núm 114/2007), que estima parcialmente la impugnación directa promovida contra diversos preceptos del Real Decreto 240/2007, de 16 de febrero, sobre entrada, libre circulación y residencia en Espańa de ciudadanos de los Estados miembros de la Unión Europea y de otros Estados parte en el Acuerdo sobre el Espacio Económico Europeo. Como apunta D. Sarmiento (2016: 329), tal doctrina, limitada en nuestro país a la expulsión del ordenamiento jurídico de la disposición de carácter general, es de aplicación obligada sobre la base del mandato de anulación afirmado en la temprana Sentencia del Tribunal de Justicia de 4 de abril de 1974, asunto 167/73, Comisión c. República Francesa (ap. 41). 
bunal Constitucional más pronto que tarde ${ }^{82}$. La misma apertura podría producirse, en la línea de la jurisprudencia italiana, en relación con la vulneración de disposiciones del ordenamiento comunitario carentes de eficacia directa, pues ello tampoco supone menoscabo alguno del papel del órgano jurisdiccional ordinario como juez europeo: la construcción del Tribunal de Justicia en relación con los remedios subsidiarios de la interpretación conforme y la responsabilidad extracontractual del Estado ${ }^{83}$ puede convivir pacíficamente con una intervención fiscalizadora de la jurisdicción constitucional nacional como la aquí defendida. Tampoco es descartable, por último, la configuración de un cauce procesal específico, de estructura similar a la cuestión de ilegalidad, que permita al juez ordinario, una vez acordada por sentencia firme la inaplicación de la ley nacional que se estima contraria a la norma europea, promover el pronunciamiento del Tribunal Constitucional sobre la conformidad de aquella al canon jurídico-comunitario, declarando eventualmente su nulidad o la exclusión de su aplicabilidad a los supuestos en que deba operar la disposición del derecho de la Unión que resulte vulnerada ${ }^{84}$. Las innegables ventajas que, en términos de seguridad jurídica, presenta tal declaración (ya de consecuencias anulatorias, ya de precisión del ámbito en que puede operar la disposición nacional), dotada de efectos erga omnes, con respecto a la ley que, por inválida, se encuentra llamada en otro caso a conocer una (in)aplicación potencialmente desigual, no hacen sino abonar la anterior conclusión.

No deben tampoco infravalorarse los desarrollos que la cuestión está conociendo en el panorama científico alemán, en el que las implicaciones del principio de primacía han recibido un tratamiento semejante al dispensado en España. Si bien desde una óptica radicalmente diferente a la de las líneas doctrinales apenas mencionadas y con un alcance mucho más restrictivo, se ha constatado el desapoderamiento sufrido por la jurisdicción constitucional en materia de protección iusfundamental a partir de la atribución de rango primario a la Carta, toda vez que se confirma la tendencia a la uniformización de los estándares de protección y a que su defensa pivote sobre las intervenciones del juez nacional ordinario y del Tribunal de Justicia, y frente a ello se ha

82 Véase, en nuestra doctrina, A. Mangas Martín y D. Liñán Nogueras (2015: 490).

83 Entre las resoluciones del Tribunal de Justicia más recientes sobre esta gradación de remedios jurídicos frente al incumplimiento de la obligación de transposición de las Directivas europeas no susceptibles de invocación directa por el ciudadano véase la Sentencia de 15 de enero de 2014, asunto C-176/12, Association de médiation sociale yotros.

84 De hecho, tal fue la propuesta, como recuerda R. Alonso García (2014: 331), formulada por el Consejo de Estado en su Informe de 14 de febrero de 2008 sobre la inserción del derecho europeo en el ordenamiento español. 
propuesto la revitalización del papel del Bundeverfassungsgericht a través de la intensificación de su implicación desde la perspectiva europea, con un mayor protagonismo en el diálogo jurisdiccional y, lo que a efectos de este trabajo especialmente interesa, por medio de la europeización del parámetro de control de la ley interna ${ }^{85}$. Razonamiento, en realidad, que no cabe descartar que se encuentre en la base de los conocidos desarrollos de la última jurisprudencia del Tribunal Constitucional español, que el mismo debería, en nuestra opinión, no limitar al ámbito del recurso de amparo.

Esta última referencia conecta con una reflexión de notable interés: la consideración del Tribunal Constitucional como juez europeo podría poner en peligro su condición de intérprete supremo de las garantías constitucionales (singularmente, de los derechos fundamentales), toda vez que la solidez de su doctrina en la materia es debida, en buena medida, al carácter cuantitativamente limitado de su parámetro de control. Ante un tal riesgo (por lo demás discutible, dado que, como con acierto se ha recordado en el contexto doctrinal italiano, la amplitud con que el Tribunal de Justicia admite la interpretación conforme del ordenamiento interno a la Directiva no transpuesta correctamente convierte la intervención de la jurisdicción constitucional en un mecanismo activable tan solo en supuestos límite ${ }^{86}$ ) se podría reaccionar, en nuestra opinión, de tres maneras. Cabría, en primer lugar, circunscribir la apertura del parámetro de constitucionalidad de la ley a la normativa europea en materia de protección iusfundamental ${ }^{87}$, explotando así las potencialidades del artículo 10.2 CE. Sería posible, en segundo lugar, limitar la intervención de la jurisdicción constitucional en este ámbito ya a las vulneraciones manifiestas del derecho de la Unión, en la línea de la jurisprudencia francesa (que ha alcanzado esta conclusión, como sabemos, siguiendo una lógica argumental bien diferente), ya a los supuestos de inobservancia radical del sistema jurídico comunitario, es decir, a los casos en que no se trate de una mera falta de adaptación del ordenamiento interno al europeo, sino de una intervención a partir de la que se deduzca de forma inequívoca la voluntad del legislador de desconocer los fundamentos nucleares del derecho originario, en la línea de la excepción, que ya nos es conocida, afirmada en la sentencia Granital por la Corte costituzionale ${ }^{88}$. Una tercera vía, más acorde,

85 Véase, en este sentido, M. Bäcker (2015), «Das Grundgesetz als Implementationsgarant der Unionsgrundrechte», EuropaRecht, págs. 389-414 (esp. págs. 404-405). Cfr. R. Mastroianni (2007), "Conflitti tra norme interne e norme comunitarie non dotate di efficacia diretta: il ruolo della Corte costituzionale», Il diritto dell'Unione europea, págs. 585-608 (pág. 602).

87 Así lo ha propuesto, en la doctrina francesa, E. Bruce (2005: 554-555).

88 Esta última propuesta no es, en nuestra doctrina, nueva, sino que fue hace ya unos años formulada por R. Alonso García (2006), «Los Tribunales Constitucionales y el 
desde nuestro punto de vista, con la lógica del funcionamiento del sistema jurisdiccional europeo, sería la de convertir en regla general lo que es aún la excepción: el planteamiento de la cuestión prejudicial por parte de los Tribunales Constitucionales nacionales. La profundización en el diálogo judicial en este nivel impulsaría un muy significativo avance en la interpretación del derecho de la Unión Europea y, al mismo tiempo, facilitaría enormemente la labor cuya asimilación por la jurisdicción constitucional española se defiende en este trabajo.

Un último apunte. El análisis de las experiencias francesa e italiana no prueba tan solo las posibilidades que ofrece un replanteamiento del papel del Tribunal Constitucional como garante del ordenamiento jurídico europeo a través del control de validez de la ley nacional, sino también que dicha revisión depende por entero de la actitud de la jurisdicción constitucional ante el fenómeno comunitario. Hemos visto cómo la jurisprudencia italiana en la materia se forjó con anterioridad a la introducción de una mención en la Constitución de la sujeción del legislador interno a los vínculos de derecho europeo y cómo la reforma de 2001 no alteró en absoluto el tratamiento que el problema recibe en aquel sistema. Del mismo modo, la revisión constitucional francesa de 1992 no se tradujo inmediatamente en una rectificación de la jurisprudencia del Conseil, que reconoce tan solo a la obligación de transposición de las directivas el carácter de obligación constitucional pese a basar una tal declaración en un precepto de alcance potencialmente mucho más amplio, como continúa señalando la doctrina de aquel país ${ }^{89}$. Por otro lado, el modelo probablemente más acabado de europeización del texto constitucional, el Europa-Artikel alemán, no ha provocado, en fin, reconsideración alguna de la cuestión por parte del Bundesverfassungsgericht. No ha de esperar, por consiguiente, nuestro Tribunal Constitucional a que la subordinación de la ley interna al derecho de la Unión se extienda más allá del en este punto tan discutible nuevo artículo $135 \mathrm{CE}$ : el fundamento de esta ampliación competencial se encuentra en la cláusula de apertura del artículo 93 CE.

control del Derecho interno conectado con el comunitario", Revista General de Derecho Administrativo, 11, págs. 1-23 (págs. 13-14).

89 Cfr. en este sentido, por todos, la sólida crítica de X. Magnon (2010: 773-774). 